\title{
A deep insight into the sialotranscriptome of the mosquito, Psorophora albipes
}

\author{
Andrezza C Chagas' ${ }^{1}$ Eric Calvo', Claudia M Rios-Velásquez², Felipe AC Pessoa², Jansen F Medeiros ${ }^{3}$ \\ and José MC Ribeiro ${ }^{1 *}$
}

\begin{abstract}
Background: Psorophora mosquitoes are exclusively found in the Americas and have been associated with transmission of encephalitis and West Nile fever viruses, among other arboviruses. Mosquito salivary glands represent the final route of differentiation and transmission of many parasites. They also secrete molecules with powerful pharmacologic actions that modulate host hemostasis, inflammation, and immune response. Here, we employed next generation sequencing and proteome approaches to investigate for the first time the salivary composition of a mosquito member of the Psorophora genus. We additionally discuss the evolutionary position of this mosquito genus into the Culicidae family by comparing the identity of its secreted salivary compounds to other mosquito salivary proteins identified so far.
\end{abstract}

Results: Illumina sequencing resulted in 13,535,229 sequence reads, which were assembled into 3,247 contigs. All families were classified according to their in silico-predicted function/ activity. Annotation of these sequences allowed classification of their products into 83 salivary protein families, twenty (24.39\%) of which were confirmed by our subsequent proteome analysis. Two protein families were deorphanized from Aedes and one from Ochlerotatus, while four protein families were described as novel to Psorophora genus because they had no match with any other known mosquito salivary sequence. Several protein families described as exclusive to Culicines were present in Psorophora mosquitoes, while we did not identify any member of the protein families already known as unique to Anophelines. Also, the Psorophora salivary proteins had better identity to homologs in Aedes (69.23\%), followed by Ochlerotatus (8.15\%), Culex (6.52\%), and Anopheles (4.66\%), respectively.

Conclusions: This is the first sialome (from the Greek sialo = saliva) catalog of salivary proteins from a Psorophora mosquito, which may be useful for better understanding the lifecycle of this mosquito and the role of its salivary secretion in arboviral transmission.

\section{Background}

Psorophora mosquitos-commonly known as "giant mosquitoes"-belong to the subfamily Culicinae, which includes many genera with epidemiologic importance to humans and animals such as Aedes, Ochlerotatus, Haemagogus, and Culex. Notably, members of the Psorophora genus are found only in the New World. Psorophora mosquitoes are opportunistic, having mammals and birds as the main hosts of their blood-feeding $[1,2]$. Psorophora females have been associated with

\footnotetext{
*Correspondence: jribeiro@nih.gov

'Laboratory of Malaria and Vector Research, National Institute of Allergy and Infectious Diseases, National Institutes of Health, Rockville, MD, USA Full list of author information is available at the end of the article
}

transmission of equine encephalitis virus, West Nile fever virus, and other arboviruses [3-9].

The phylogeny of mosquitoes includes three subfamilies within the Culicidae: Anophelinae, Culicinae, and Toxorhynchitinae. Studies based on the morphology, behavior, biogeographic distribution, and life-history suggest the Anophelinae subfamily as monophyletic and basal into the Culicidae family. On the other hand, the Culicinae subfamily includes the majority of remaining mosquito genera distributed into ten tribes. Psorophora mosquitoes share the tribe Aedini together with Aedes, Ochlerotatus, and other mosquito genera, while Culex mosquitoes belong to the Culicini tribe. Previous studies have supported the genera from the tribe Culicini as basal to genera of the tribe Aedini [10]. These results are

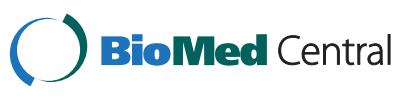


in agreement with the phylogeny proposed by Besansky and Fahey [11]. The Psorophora genus contains 48 species divided into three subgenera: Grabhamia (15 species), Janthinosoma (23 species), and Psorophora (10 species) [12]. Recently, morphologic and molecular studies have supported Psorophora as a sister group with Aedes/Ochlerotatus [13-15]. In contrast, studies using $18 \mathrm{~S}$ rDNA sequence have suggested Psorophora species as a sister group to Culex and/or to Aedes/Ochlerotatus species $[12,16]$.

The salivary glands (SGs) of hematophagous insects secrete a cocktail of biochemically active compounds [17] that interacts with hemostasis [18-21], immunity, and inflammation of their hosts [22,23]. Perhaps because of the continuous contact of mosquito salivary proteins with host immunity, salivary proteins are at a fast pace of evolution and divergence, even in closely related species [24]. In the past decade, the continuous advances in the fields of transcriptome and proteome analysis led to the development of high-throughput sialotranscriptome studies (from the Greek sialo= saliva) [23,25]. These studies resulted in a large database of secreted salivary proteins from different blood-feeding arthropod families including members of the Culicidae family.

All mosquito sialotranscriptome studies so far have targeted members of the Aedes, Ochlerotatus, Anopheles, and Culex genera [24], which are important vectors of human and animal diseases. Although some Psorophora species are known to be vectors of several arboviruses, the molecular composition of their salivary secretion remains unknown. Our primary aim was to investigate the salivary transcriptome and proteome of a member of the Psorophora genus (Psorophora albipes) to ultimately better understand the evolution of SG composition within the Culicidae family. In addition, our work makes available the first platform of salivary proteins from this mosquito genus, relevant for improving our understanding of mosquito evolution, the evolving risks in public health due to the recent expansions of Psorophora mosquitoes to the North, and for development of exposure markers to mosquito bites and to vector-borne diseases transmitted by mosquitoes.

\section{Methods}

Mosquitoes

Psorophora mosquitoes were collected in fragments of unflooded rain forest in Manacapuru municipality, Amazonas state, Brazil, using modified CDC traps. The mosquitoes were maintained with water and sugar solution and transported to Biodiversity Laboratory of Leônidas and Maria Deane Institute (Fiocruz/Manaus). The mosquitoes were identified using the taxonomic keys proposed by Forattini [12] and Consoll and Lourenco de Oliveira [26].

\section{Dissection and RNA extraction}

SGs from $P$. albipes (50 pairs) were dissected in $150 \mathrm{mM}$ sodium chloride $\mathrm{pH} 7.4$ and immediately transferred to $50 \mu \mathrm{l}$ RNAlater ${ }^{\circ}$ solution and maintained at $4^{\circ} \mathrm{C}$ until the RNA extraction. SG RNA was extracted and isolated using the Micro-FastTrack ${ }^{\mathrm{Tm}}$ mRNA isolation kit (Invitrogen, San Diego, CA) per manufacturer's instructions. The integrity of the total RNA was checked on a Bioanalyser (Agilent Technologies Inc., Santa Clara, CA).

\section{Next-Generation Sequencing (NGS) and \\ bioinformatic analysis}

The SG library was constructed using the TruSeq RNA sample prep kit, v2 (Illumina Inc., San Diego, CA). The resulting cDNA was fragmented using a Covaris E210 focused ultrasonicator (Covaris, Woburn, MA). Library amplification was performed using eight cycles to minimize the risk of over-amplification. Sequencing was performed on a HiSeq 2000 (Illumina) with v3 flow cells and sequencing reagents. One lane of the HiSeq machine was used for this and two other libraries, distinguished by bar coding. A total of 135,651,020 sequences of $101 \mathrm{nt}$ in length were obtained. A paired-end protocol was used. Raw data were processed using RTA 1.12.4.2 and CASAVA 1.8.2. mRNA library construction, and sequencing was done by the NIH Intramural Sequencing Center (NISC). Reads were trimmed of low-quality regions $(<10)$ and were assembled together with the assembly by short sequences (ABySS) software (Genome Sciences Centre, Vancouver, BC, Canada) [27,28] using various kmer (k) values (every even number from 24 to 96). Because the ABySS assembler tends to miss highly expressed transcripts [29], the Trinity assembler [30] was also used. The resulting assemblies were joined by an iterative BLAST and cap3 assembler [31]. Sequence contamination between bar-coded libraries were identified and removed when their sequence identities were over $98 \%$, but their abundance of reads were $>50$ fold between libraries. Coding sequences (CDS) were extracted using an automated pipeline, based on similarities to known proteins, or by obtaining CDS containing a signal peptide [32]. Coding and their protein sequences were mapped into a hyperlinked Excel spreadsheet (presented as Additional file 1, and also located at http://exon.niaid.nih.gov/transcriptome/Psorophora_albipes/Pso-s2-web.xlsx.). Signal peptides, transmembrane domains, furin cleavage sites, and mucin-type glycosylation were determined with software from the Center for Biological Sequence Analysis (Technical University of Denmark, Lyngby, Denmark) [32-35]. Reads were mapped into the contigs using blastn [36] with a word size of 25, masking homonucleotide decamers and allowing mapping to up to three different CDS if the BLAST results had the same score values. Mapping of the reads was also included 
in the Excel spreadsheet. Automated annotation of proteins was based on a vocabulary of nearly 250 words found in matches to various databases-including Swissprot, Gene Ontology, KOG, PFAM, and SMART, and a subset of the non-redundant protein database of the NCBI containing proteins from vertebrates. Further manual annotation was done as required. Detailed bioinformatics analysis of our pipeline can be found in our previous publication [31]. Sequence alignments were done with the ClustalX software package [37]. Phylogenetic analysis and statistical neighbor-joining bootstrap tests of the phylogenies were done with the Mega package [38]. Blast score ratios were done as indicated previously [39]. For visualization of synonymous and nonsynonymous sites within coding sequences, the tool BWA aln [40] was used to map the reads to the CDS, producing SAI files that were joined by BWA sampe module, converted to BAM format, and sorted. The sequence alignment/map tools (samtools) package [41] was used to do the mpileup of the reads (samtools mpileup), and the binary call format tools (bcftools) program from the same package was used to make the final vcf file containing the single-nucleotide polymorphic (SNP) sites, which were only taken if the site coverage was at least 100 (-D100), the quality was 13 or better and the SNP frequency was 5 or higher (default). Determination of whether the SNPs lead to a synonymous or non-synonymous codon change was achieved by a program written in Visual Basic by JMCR, the results of which are mapped into the Excel spreadsheet and color visualized in hyperlinked rtf files within Additional file 1.

\section{Proteome analysis}

Fifty SG pairs from female $P$. albipes were used in the proteome analysis. Briefly, the glands were sonicated and the supernatant was boiled for $10 \mathrm{~min}$ in reducing Laemmli gel-loading buffer and subsequently resolved on a NuPAGE 4-12\% Bis-Tris precast gradient gel. Proteins were visualized with SimplyBlue stain (Invitrogen). The gel was arbitrary sliced into 19 individual sections (coded as F1-19) that were destained and digested overnight with trypsin at $37^{\circ} \mathrm{C}$. ZipTips ${ }^{\oplus}$ (Millipore, Belford, MA) were used to extract and desalt the peptides, which were resuspended in $0.1 \%$ TFA before mass spectrometry analysis (MS).

Nanoflow reverse-phase liquid chromatography coupled with tandem MS (MS/MS) was performed as described [42]. We obtained a database of the tryptic peptides identified by MS as a final product. This was used to search for matches from our transcriptome database of $P$. albipes. Additional details about the proteome procedure and analysis can be found in the methodology described in Chagas et al. [42].

\section{Results and discussion}

\section{Exploring the sialotranscriptome of a Psorophora mosquito}

Assembly of $135,651,020$ reads into 43,466 contigs (see assembly details in Additional file 2) allowed the extraction of 3,247 CDS (which mapped 13,535,229 reads) which in turn were classified according to their primary sequence (presence of homology to an already described sequence) into three categories: $i$ ) transcripts encoding for secreted (S) proteins, $i$ ) transcripts encoding for housekeeping $(\mathrm{H})$ proteins, and $i i i)$ transcripts encoding for proteins of unknown (U) function that lack homology with any functionally characterized protein from another organism (Table 1). Notice that these 3,247 CDS contain 485 similar CDS divergent by a few amino acids, which can be verified in the clusterization column grouping protein sequences with $95 \%$ similarity on $50 \%$ of their lengths. These may represent allele products, recent gene duplications, or sequencing/assembly errors.

After annotation, 7,537,805 reads $(55.69 \%$ of the reads mapped to CDS) were classified as originating from transcripts encoding putative $\mathrm{S}$ proteins, and these were assembled into 802 contigs $(24.70 \%$ of the total contigs) (Table 1). Signal peptide was detected in these contig sequences, suggesting that these contigs encode for proteins secreted in the saliva. In addition, 5,473,151 transcript reads $(40.44 \%$ of the total reads) mapped to transcripts encoding $\mathrm{H}$ proteins, which were assembled into 1,973 contigs $(60.76 \%$ of the total contigs). Another 85,213 reads $(0.63 \%$ of total reads) correspond to transposable elements, and 439,060 reads $(3.24 \%$ of total reads) were classified as originating from transcripts that encode for $\mathrm{U}$ products (Table 1).

The sequences encoding for $\mathrm{H}$ proteins were further classified into 26 subgroups according to their predicted function or membership to previously described protein families (Table 2). The potentially highly expressed $\mathrm{H}$ proteins include those associated with protein synthesis machinery (14.92\% of the reads classified as H products), signal transduction proteins (5.18\% of the total reads), unknown conserved-which represent highly conserved proteins of unknown function most likely related with

Table 1 Functional classification of transcripts from salivary glands of the mosquito Psorophora albipes

\begin{tabular}{ccccc}
\hline Class & $\begin{array}{c}\text { Number of } \\
\text { coding sequences }\end{array}$ & $\begin{array}{c}\text { \% of } \\
\text { CDS }\end{array}$ & $\begin{array}{c}\text { Number of } \\
\text { reads }\end{array}$ & $\begin{array}{c}\text { \% of total } \\
\text { reads }\end{array}$ \\
\hline Secreted & 802 & 24.70 & $7,537,805$ & 55.69 \\
Housekeeping & 1,973 & 60.76 & $5,473,151$ & 40.44 \\
$\begin{array}{c}\text { Transposable } \\
\text { element }\end{array}$ & 38 & 1.17 & 85,213 & 0.63 \\
$\begin{array}{c}\text { Unknown } \\
\text { product }\end{array}$ & 434 & 13.37 & 439,060 & 3.24 \\
Total & 3,247 & 100.00 & $13,535,229$ & 100.00 \\
\hline
\end{tabular}


Table 2 Functional classification of the housekeeping products expressed in the female Psorophora albipes salivary glands

\begin{tabular}{|c|c|c|c|}
\hline Housekeeping & $\begin{array}{l}\text { Number of } \\
\text { contigs }\end{array}$ & $\begin{array}{l}\text { Number of } \\
\text { reads }\end{array}$ & $\%$ Reads \\
\hline Protein synthesis machinery & 132 & $1,711,561$ & 14.92 \\
\hline Signal transduction & 283 & 594,284 & 5.18 \\
\hline Unknown conserved & 265 & 372,425 & 3.25 \\
\hline Transporters and channels & 192 & 364,580 & 3.18 \\
\hline Lipid metabolism & 90 & 326,204 & 2.84 \\
\hline Transcription machinery & 122 & 292,742 & 2.55 \\
\hline Protein export & 136 & 236,848 & 2.06 \\
\hline Cytoskeletal proteins & 100 & 202,027 & 1.76 \\
\hline Protein modification & 68 & 185,852 & 1.62 \\
\hline Extracellular matrix & 65 & 159,217 & 1.39 \\
\hline Storage & 14 & 149,093 & 1.30 \\
\hline $\begin{array}{l}\text { Unknown conserved with } \\
\text { transmembrane domains }\end{array}$ & 51 & 140,420 & 1.22 \\
\hline Energy metabolism & 76 & 98,777 & 0.86 \\
\hline Carbohydrate metabolism & 55 & 96,997 & 0.85 \\
\hline Proteases & 45 & 94,848 & 0.83 \\
\hline Amino acid metabolism & 28 & 83,082 & 0.72 \\
\hline Proteasome machinery & 85 & 76,054 & 0.66 \\
\hline Intermediary metabolism & 10 & 60,190 & 0.52 \\
\hline Native immunity & 21 & 27,736 & 0.51 \\
\hline $\begin{array}{l}\text { Signal transduction - } \\
\text { apoptosis }\end{array}$ & 37 & 50,036 & 0.44 \\
\hline Transcription factor & 26 & 33,506 & 0.29 \\
\hline Nucleotide metabolism & 15 & 33,498 & 0.29 \\
\hline Nuclear regulation & 22 & 31,366 & 0.27 \\
\hline $\begin{array}{l}\text { Oxidant metabolism/ } \\
\text { Detoxification }\end{array}$ & 19 & 22,649 & 0.20 \\
\hline Nuclear export & 6 & 16,187 & 0.14 \\
\hline Detoxification & 10 & 12,972 & 0.11 \\
\hline Total & 1973 & $5,473,151$ & 47.71 \\
\hline
\end{tabular}

cellular function (3.25\% of the total reads), transporters and channels (3.18\% of total reads), and proteins with a potential role in lipid metabolism $(2.84 \%$ of the total reads). Because SGs are specialized in secretion, high expression of transcripts encoding for constituents of protein synthesis machinery and energy metabolism is commonly observed in similar analyses of blood-feeding arthropod sialotranscriptomes. Here energy metabolism represents only $0.86 \%$ of the total transcript reads encoding for $\mathrm{H}$ products.

The putative $\mathrm{S}$ proteins were further divided into 16 general categories (Table 3), several of which were abundantly expressed in $P$. albipes SGs at the transcriptome level. Their members had a classic secretion signal:
Table 3 Functional classification of transcripts coding for putative secreted proteins in female Psorophora albipes salivary glands

\begin{tabular}{|c|c|c|}
\hline \multirow[t]{2}{*}{ Secreted } & \multicolumn{2}{|c|}{ Number of } \\
\hline & Contigs & Reads \\
\hline
\end{tabular}

\section{Enzymes}

Glycosidases

$681,837 \quad 9.05$

5' nucleotides/Apyrase family

Serine proteases

Cathepsins

Serine-type carboxypeptidases

Mosquito lipases

Alkaline phosphatases

Adenosine deaminase family

Endonucleases

Ribonucleases

Destabilase family

Hyaluronidases

$\begin{array}{ccc}7 & 681,837 & 9.05 \\ 6 & 41,550 & 0.55 \\ 5 & 40,574 & 0.54 \\ 3 & 36,397 & 0.48 \\ 2 & 20,779 & 0.28 \\ 1 & 9,608 & 0.13 \\ 2 & 8,087 & 0.11 \\ 1 & 6,885 & 0.09 \\ 4 & 6,281 & 0.08 \\ 3 & 2,417 & 0.03 \\ 1 & 842 & 0.01 \\ 1 & 372 & 0.00\end{array}$

Ubiquitous protease inhibitor domains

Serpin family
Kazal domain-containing
peptides
TIL domain family found in
mosquitoes
Metalloproteinase inhibitors
Schistocerca protease inhibitor
Cystatins-may be
housekeeping
Immunity-related proteins

$\begin{array}{ccc}15 & 169,094 & 2.24 \\ 13 & 46,712 & 0.62 \\ 8 & 38,268 & 0.51 \\ 1 & 2,029 & 0.03 \\ 1 & 2,023 & 0.03 \\ 1 & 175 & 0.00\end{array}$

$\begin{array}{llll}\text { Fred/Ficolin domain-containing } \quad 9 & 65,681 & 0.87\end{array}$ proteins

Lysozymes
C type lectins
Peptidoglycan recognition
domains

$\begin{array}{llll}\text { Gram-negative binding proteins } & 1 & 5,968 & 0.08 \\ \text { ML domains } & 3 & 4,480 & 0.06 \\ \text { Gambicin } & 2 & 4,360 & 0.06 \\ \text { Leucine-rich proteins } & 1 & 1,249 & 0.02 \\ \text { Cecropins } & 1 & 277 & 0.00 \\ \text { Defensin } & 1 & 275 & 0.00 \\ \text { Galectin-maybe housekeeping } & 1 & 173 & 0.00\end{array}$

Mucins

$\begin{array}{lccc}\text { Mucin I mosquito family } & 22 & 1,866,771 & 24.77 \\ \text { gSG5 mucin protein family } & 8 & 60,819 & 0.81 \\ \text { Aedes-specific mucins } & 7 & 30,550 & 0.41 \\ \text { Other mucins } & 8 & 24,225 & 0.32\end{array}$


Table 3 Functional classification of transcripts coding for putative secreted proteins in female Psorophora albipes salivary glands (Continued)

\begin{tabular}{|c|c|c|c|}
\hline Virus-induced mucins & 1 & 11,007 & 0.15 \\
\hline SG3 mucin family & 2 & 2,197 & 0.03 \\
\hline Peritrophin/chitin binding & 3 & 1,587 & 0.02 \\
\hline Simulium mucins & 3 & 1,320 & 0.02 \\
\hline \multicolumn{4}{|l|}{ OBP superfamily } \\
\hline Long-D7 mosquito family & 26 & 297,507 & 3.95 \\
\hline Culicine short-D7 proteins & 23 & 156,429 & 2.08 \\
\hline Salivary mosquito OBP & 2 & 1,028 & 0.01 \\
\hline Yellow Phlebotomine family & 2 & 7,763 & 0.10 \\
\hline \multicolumn{4}{|l|}{$\begin{array}{l}\text { Ubiquitous protein families } \\
\text { existing outside Nematocera, } \\
\text { function unknown }\end{array}$} \\
\hline Antigen-5 family & 13 & 257,852 & 3.42 \\
\hline $\begin{array}{l}\text { Aedes hypothetical secreted } \\
\text { conserved proteins }\end{array}$ & 3 & 5,605 & 0.07 \\
\hline $\begin{array}{l}\text { 12- to } 14-k D a \text { mosquito family } \\
\text { similar to Drosophila proteins }\end{array}$ & 4 & 3,609 & 0.05 \\
\hline 15- to $17-\mathrm{kDa}$ insect family & 1 & 816 & 0.01 \\
\hline Culex/Drosophila WAP subfamily & 1 & 283 & 0.00 \\
\hline \multicolumn{4}{|l|}{$\begin{array}{l}\text { Protein families exclusive of } \\
\text { bloodsucking Nematocera }\end{array}$} \\
\hline $\begin{array}{l}30 \mathrm{kDa} / \text { Aegyptin family - } \\
\text { Mosquitoes and black flies }\end{array}$ & 5 & 197,279 & 2.62 \\
\hline Canonical & 8 & 109,171 & 1.45 \\
\hline Mucin II mosquito family & 2 & 9,705 & 0.13 \\
\hline \multicolumn{4}{|l|}{$\begin{array}{l}\text { Protein families specific to } \\
\text { mosquitoes }\end{array}$} \\
\hline HHH peptide family & 18 & 576,548 & 7.65 \\
\hline 30.5-kDa protein & 4 & 327,913 & 4.35 \\
\hline hyp8.2 Culicine family & 6 & 98,361 & 1.30 \\
\hline 9.7-kDa family & 17 & 63,969 & 0.85 \\
\hline Aedes W-rich peptides & 1 & 51,783 & 0.69 \\
\hline Aedes $6.5-8.5$ protein family & 3 & 43,900 & 0.58 \\
\hline Aedes 62-kDa family & 6 & 41,700 & 0.55 \\
\hline Basic tail mosquito family & 6 & 32,687 & 0.43 \\
\hline 34-kDa Aedes family & 8 & 30,082 & 0.40 \\
\hline $\begin{array}{l}\text { Aedes/Anopheles darlingi 14-15 } \\
\text { family }\end{array}$ & 6 & 25,350 & 0.34 \\
\hline GQ-rich Culicine family & 3 & 8,203 & 0.11 \\
\hline $23.5 \mathrm{kDa}$ Culicine family & 4 & 8,099 & 0.11 \\
\hline gSG8 family & 1 & 3,237 & 0.04 \\
\hline Hyp6.2 family & 3 & 2,291 & 0.03 \\
\hline Culex WRP/16-kDa family & 2 & 2,138 & 0.03 \\
\hline Salivary protein 16 family & 2 & 1,778 & 0.02 \\
\hline $\mathrm{HHH}$ family 2 & 3 & 1,432 & 0.02 \\
\hline Anopheline SG1 family & 1 & 273 & 0.00 \\
\hline
\end{tabular}

Table 3 Functional classification of transcripts coding for putative secreted proteins in female Psorophora albipes salivary glands (Continued)

\begin{tabular}{|c|c|c|c|}
\hline \multicolumn{4}{|l|}{$\begin{array}{l}\text { Protein families specific to black } \\
\text { flies }\end{array}$} \\
\hline $\begin{array}{l}\text { Simulium disintegrin similar to } \\
\text { phenoloxidase inhibitor peptides }\end{array}$ & 1 & 15,887 & 0.21 \\
\hline $\begin{array}{l}\text { H-rich, acidic proteins of } \\
\text { Simulium }\end{array}$ & 1 & 861 & 0.01 \\
\hline $\begin{array}{l}\text { Salivary-orphan proteins of } \\
\text { conserved secreted families }\end{array}$ & 9 & 11,269 & 0.15 \\
\hline \multicolumn{4}{|l|}{ Deorphanized proteins } \\
\hline $\begin{array}{l}\text { Similar to OT-19-contains HH } \\
\text { repeats }\end{array}$ & 16 & 772,288 & 10.25 \\
\hline Aedes 5-kDa family & 7 & 125,986 & 1.67 \\
\hline Aedes 7-kDa family & 4 & 2,378 & 0.03 \\
\hline \multicolumn{4}{|l|}{$\begin{array}{l}\text { Families not reported on } \\
\text { Nematocera - sialome review }\end{array}$} \\
\hline Lipocalins & 5 & 23,805 & 0.32 \\
\hline SGS family & 4 & 4,869 & 0.06 \\
\hline \multicolumn{4}{|l|}{ Novel families } \\
\hline Pso 4.7 kDa & 6 & 47,608 & 0.63 \\
\hline Pso 4.01 kDa ultrashort-D7 family & 3 & 11,185 & 0.15 \\
\hline Pso 4.2 kDa & 12 & 4,201 & 0.06 \\
\hline Pso 6.3 kDa & 3 & 3,398 & 0.05 \\
\hline Pso 12 kDa & 3 & 1,289 & 0.02 \\
\hline $\begin{array}{l}\text { Pso } 12.8 \mathrm{kDa} \text { - novel mosquito } \\
\text { peptide family }\end{array}$ & 2 & 1,217 & 0.02 \\
\hline $\begin{array}{l}\text { Pso } 20.44 \mathrm{kDa} \text { - unique to } \\
\text { Culicine }\end{array}$ & 1 & 290 & 0.00 \\
\hline Pso 4.69 kDa-unique to Aedes & 1 & 103 & 0.00 \\
\hline Other putative secreted proteins & 371 & 814,858 & 10.81 \\
\hline Total secreted & 802 & $7,537,805$ & \\
\hline
\end{tabular}

mucin I mosquito family (24.77\% of total reads classified as $\mathrm{S}$ products), similar to OT-19 containing $\mathrm{HH}$ repeats family $(10.25 \%$ of total reads), glycosidases $(9.05 \%$ of total reads), $\mathrm{HHH}$ peptide family (peptides containing a His triad) (7.65\% of total reads), $30.5-\mathrm{kDa}$ family $(4.35 \%$ of total reads), long-D7 mosquito family (3.95\% of total reads), Antigen-5 family (3.42\% of total reads), Aegyptin family (2.62\% of total reads), Serpin family $(2.24 \%$ of total reads), Culicine short-D7 protein family $(2.08 \%$ of total reads), Aedes $5-\mathrm{kDa}$ family (1.67\% of total reads), $41-\mathrm{kDa}$ canonical family ( $1.45 \%$ of total reads), and Hyp 8.2 Culicine family (1.30\% of total reads) (Table 3 ). Additionally, eight novel protein families were described in $P$. albipes with either no significant matches to any sequence deposited in the NCBI database, or matching mosquito hypothetical proteins not previously described in sialotranscriptomes; these were named Psor $4.7 \mathrm{kDa}$, Psor $4.2 \mathrm{kDa}$, Psor $12 \mathrm{kDa}$, Psor $6.3 \mathrm{kDa}$, Psor $4.01 \mathrm{kDa}$ 
ultrashort-D7 family, Psor $12.8 \mathrm{kDa}$ novel mosquito peptide family, Psor $4.69 \mathrm{kDa}$ weakly similar to Aedes, and Psor 20.44 kDa weakly similar to Culicine. These new protein families account for $1 \%$ of all the transcripts reads of $P$. albipes SG transcriptome. A summary and details related to the transcript annotation encoding for $\mathrm{S}$ proteins can be found in Table 3 and in Additional file 1.

\section{Proteomics analysis of $P$. albipes SGs}

We employed a proteomics analysis to investigate protein expression in SGs of $P$. albipes. After Coomassie staining, five bands were revealed as strongly stained at approximate molecular weight (MW) near $191 \mathrm{kDa}, 64$ to $51 \mathrm{kDa}$, between 51 to $39 \mathrm{kDa}$, between 39 to $28 \mathrm{kDa}$, and one last band with an estimated MW of $28 \mathrm{kDa}$. Other bands with lesser stain intensity were also revealed in the gel (Figure 1). The NuPage gel was arbitrary cut into 19 fractions and submitted to MS/MS analysis. Contigs showing up two or more tryptic peptides were identified by using the $P$. albipes transcriptome database. Table 4 presents the details of all secreted contigs identified in the $P$. albipes SG proteome.

We confirmed expression of 20 of 83 (24.09\%) S protein families described in the sialotranscriptome. The three strongly stained bands of the gel apparently match to: F9 (glycosidase family), F11 (apyrase, adenosine deaminase), F15 (long-D7 mosquito family, 30-kDa Aegyptin family, Antigen-5). To conclude, six of ten protein families described as highly expressed in our $P$. albipes SG transcriptome (glycosidases, 30.5-kDa family, longD7 mosquito family, 30-kDa Aegyptin-like family, Serpin family, and Culicine D7 mosquito family, respectively) were confirmed to be present in the salivary proteome of $P$. albipes based on our subsequent proteomics analysis. Furthermore, seven families (35\% of the total families confirmed by proteome) described in the transcriptome as specific for mosquitoes (basic tail mosquito, Aedes 62 kDa, 9.7-kDa family, Hyp8.2 Culicine, $30.5-\mathrm{kDa}$ family, $23.5-\mathrm{kDa}$ family, Aedes $34 \mathrm{kDa}$ ) were also confirmed by our proteome analysis. Additionally, the proteomics analysis confirmed the presence of the newly described protein family named as "Psor-4 $\mathrm{kDa}$ ultrashort-D7 family-Contig Psor-9075." More details about contigs/families found in the proteome of Psorophora can be seen in Figure 1 and Table 4. Tryptic peptides were assigned to several contigs encoding for $\mathrm{H}$ proteins (Additional file 1) such as a $P$. albipes Sphingomyelin phosphodiesterase that shows 55\% amino acid identity to the homolog/ortholog from Culex quinquefasciatus. Previous proteomic studies using mosquito SGs identified some abundant protein families in Aedes aegypti such as long-D7 protein, adenosine deaminase, serpin, and 30-kDa Aegyptin [43]. Members of all these

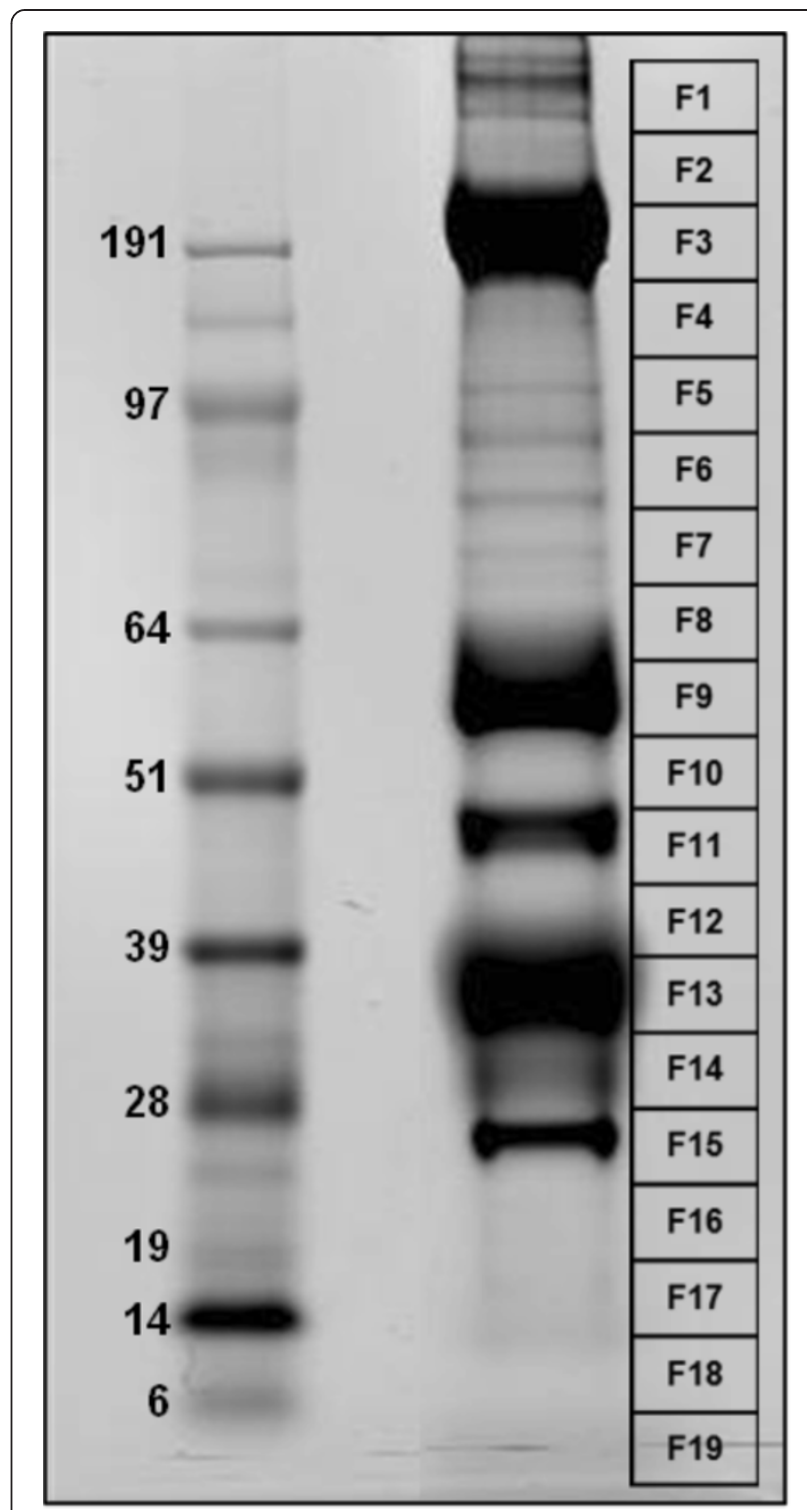

Figure 1 Salivary gland proteins from the mosquito Psorophora albipes. The left gel lane shows the protein standards with their molecular weights $(\mathrm{kDa})$. The right gel lane shows the $P$. albipes salivary proteins (Coomassie stained). The grid at the right (F1-F19) shows the area of the gel slices submitted for tryptic digest and tandem mass spectrometry identification.

families were similarly identified in our P. albipes proteome. Additionally, members of the two mosquito-specific families-known as 34-kDa and 32-kDa families-were identified in our Psorophora proteome; members of this family were described as immunogenic in the proteome study of Ae. aegypti saliva [43]. Also, the antigen-5 protein was confirmed in the Psorophora proteome, and members of this family have been previously described as a SG-secreted product in Culex [44]. Many of the identified proteins have homologs/orthologs in other mosquitoes that have been described as related to blood feeding. 
Table 4 Putative secreted proteins identified in the sialotranscriptome of Psorophora albipes and confirmed by our proteomic studies

\begin{tabular}{|c|c|}
\hline Description & Protein name | Fraction $\rightarrow$ Number of Tryptic peptides* \\
\hline $\begin{array}{l}5^{\prime} \text { nucleotidase/ } \\
\text { apyrase }\end{array}$ & Psor-13556|F11 $\rightarrow$ 8, Psor-17515|F11 $\rightarrow 8$, Psor-22761|F11 $\rightarrow 8$, Psor-17516|F11 $\rightarrow 7$, Psor-12600|F11 $\rightarrow 5$, Psor-17320|F11 $\rightarrow 4$ \\
\hline $\begin{array}{l}\text { Adenosine } \\
\text { deaminase }\end{array}$ & Psor-13638|F11 $\rightarrow 163$ \\
\hline Endonuclease & Psor-34082|F12 $\rightarrow 18$, Psor-34081|F12 $\rightarrow 18$, Psor-34084|F12 $\rightarrow 8$ \\
\hline Glycosidases & Psor-12511|F9 $\rightarrow 84$ \\
\hline Serpin & $\begin{array}{l}\text { Psor-18383|F12 } \rightarrow \text { 594, Psor-18379|F12 } \rightarrow 562, \text { Psor-18398|F12 } \rightarrow 504 \text {, Psor-18380|F12 } \rightarrow 473 \text {, Psor-20123|F12 } \rightarrow 263 \text {, Psor-20135| } \\
\text { F12 } \rightarrow 239 \text {, Psor-18402|F12 } \rightarrow 207, \text { Psor-20121|F12 } \rightarrow 159, \text { Psor-18262|F12 } \rightarrow 151 \text {, Psor-12755|F12 } \rightarrow 19\end{array}$ \\
\hline Lysozyme & Psor-13510|F19 $\rightarrow$ 7, Psor-14008|F19 $\rightarrow$ 7, Psor-12935|F19 $\rightarrow 7$, Psor-29999|F19 $\rightarrow 7$ \\
\hline gSG5 mucin & Psor-13808|F7 $\rightarrow 34$, Psor-12515|F7 $\rightarrow 29$, Psor-13816|F7 $\rightarrow 24$, Psor-21012|F7 $\rightarrow 23$, Psor-12520|F7 $\rightarrow 16$, Psor-16372|F14 $\rightarrow 3$ \\
\hline Aedes-specific mucin & Psor-24903|F14 $\rightarrow 8$ \\
\hline Long-D7 mosquito & $\begin{array}{l}\text { Psor-34191|F15 } \rightarrow 29, \text { Psor-34198|F15 } \rightarrow 28, \text { Psor-34194|F15 } \rightarrow 28, \text { Psor-34190|F15 } \rightarrow 22, \text { Psor-34202|F15 } \rightarrow 17, \text { Psor-32651|F15 } \rightarrow 9, \\
\text { Psor-16545|F14 } \rightarrow 26 \text {, Psor-14130|F14 } \rightarrow 22, \text { Psor-27735|F14 } \rightarrow 22, \text { Psor-22249|F14 } \rightarrow 22, \text { Psor-21941|F14 } \rightarrow 10, \text { Psor-14244|F14 } \rightarrow 5, \\
\text { Psor-22962|F14 } \rightarrow 5 \text {, Psor-16516|F14 } \rightarrow 4 \text {, Psor-16517|F14 } \rightarrow 3 \text {, Psor-5239|F14 } \rightarrow 2\end{array}$ \\
\hline Short-D7 Culicine & $\begin{array}{l}\text { Psor-24290|F19 } \rightarrow 11, \text { Psor-14799|F19 } \rightarrow 8, \text { Psor-24280|F19 } \rightarrow 8, \text { Psor-14821|F19 } \rightarrow 8, \text { Psor-24282|F19 } \rightarrow 8, \text { Psor-24283|F19 } \rightarrow 7 \text {, } \\
\text { Psor-11438|F19 } \rightarrow 5 \text {, Psor-33959|F19 } \rightarrow 3\end{array}$ \\
\hline Antigen-5 & Psor-12020|F16 $\rightarrow 22$, Psor-14194|F16 $\rightarrow 5$, Psor-12762|F15 $\rightarrow 7$, Psor-17302|F15 $\rightarrow 3$ \\
\hline $\begin{array}{l}\text { 30-kDa/Aegyptin } \\
\text { family }\end{array}$ & Psor-20191|F15 $\rightarrow 39$, Psor-18075|F14 $\rightarrow 19$, Psor-18076|F14 $\rightarrow 18$, Psor-18880|F14 $\rightarrow 10$, Psor-19455|F14 $\rightarrow 7$ \\
\hline Basic tail mosquito & Psor-13880|F19 $\rightarrow 3$ \\
\hline Aedes 62-kDa & Psor-23962|F18 $\rightarrow$ 7, Psor-23027|F12 $\rightarrow 4$, Psor-18121|F12 $\rightarrow 2$, Psor-15772|F12 $\rightarrow 2$, Psor-15774|F12 $\rightarrow 2$ \\
\hline 9.7-kDa family & Psor-19686|F19 $\rightarrow 5$, Psor-19685|F19 $\rightarrow 4$, Psor-19523|F19 $\rightarrow 3$, Psor-12072|F19 $\rightarrow 3$ \\
\hline Hyp8.2 Culicine & Psor-31485|F19 $\rightarrow 2$, Psor-31484|F19 $\rightarrow 2$, Psor-31419|F19 $\rightarrow 2$ \\
\hline $30.5-\mathrm{kDa}$ & Psor-14979|F15 $\rightarrow 4$ \\
\hline 23.5-kDa & Psor-16925|F17 $\rightarrow 2$ \\
\hline 34-kDa Aedes & Psor-15738|F14 $\rightarrow 2$ \\
\hline $\begin{array}{l}\text { Psor-4 kDa } \\
\text { ultrashort-D7 }\end{array}$ & Psor-9075|F19 $\rightarrow 2$ \\
\hline
\end{tabular}

Insight into the $P$. albipes Secreted Sialome

The following highlights are related to the secreted sialome of $P$. albipes compared with others from bloodsucking Nematocera.

\section{Ubiquitous protein families}

\section{Enzymes}

Members of the $5^{\prime}$-nucleotidase/apyrases, adenosine deaminase, ribonuclease, endonuclease, alkaline phosphatase, serine proteases, lipase, destabilase/lysozyme, hyaluronidase, and glycosidases were identified. Cathepsins and serine-type carboxypeptidase are also noted but could be of $\mathrm{H}$ functions. These enzymes have all been found before in mosquito sialotranscriptomes, and their role in blood and sugar feeding has been reviewed [24]. Notably in the case of Psorophora, however, is the finding of both endonuclease (identified by MS/MS in band 12) and hyaluronidase, which were previously restricted to C. quinquefasciatus [24] and sand flies, but not found in Aedes or Anopheles sialotranscriptomes. This enzyme combination may help decrease skin-matrix viscosity and diffusion of salivary components, as well as breaking down neutrophil extracellular traps [45]. Apyrase, adenosine deaminase, and glycosidases were found by MS/ MS in fraction 10, consistent with their expected sizes. Transcripts encoding for sphingomyelin phosphodiesterases (SMases) - some of which are highly transcribed with coverages higher than 500-is an unusual finding in mosquito sialotranscriptomes. Although lacking the initial methionine, Psor-15064 matches at position 6 a $C$. quinquefasciatus protein with $55 \%$ identity over 564 amino acids that has a predicted signal peptide. The SMases are members of the DNase I superfamily of enzymes responsible for breaking sphingomyelin into phosphocholine and ceramide. In addition, activation of SMase is suggested to play a role in production of 
ceramide in response to cellular stresses [46]. Tryptic peptides originating from SMase were found in fractions 11 and 12 of the NuPage gel in our proteomic analysis. The high expression of this enzyme suggests it may be secreted.

Protease inhibitor domains: Serpins were well expressed, with $2.24 \%$ of the reads of the $S$ class, and were identified by MS/MS in gel fraction 12 . The protein encoded by Psor18383 is $44 \%$ identical with the FXa-directed anticoagulant precursor of Aedes albopictus. Phylogenetic analysis indicated the presence of at least five distinct gene families (Roman numerals in Figure 2), of which clades I, II, and III are found in both culicines and anophelines (clade III also having a sand fly member), but clades IV and V are exclusively Aedine; clade IV includes the salivary Xase clotting inhibitor of Ae aegypti [47]. The targets of serpins from clades I, II, III, and V remain to be identified. It is to be noted that the salivary anticlotting of anophelines is not a serpin but rather a novel protein family of antithrombins [48,49]. TIL and Kazal domain-containing peptides may be related to additional anticlotting proteins [50] or antimicrobials. A metalloproteinase inhibitor represents the first such finding in Nematocera sialomes; Psor- 25577 is $85 \%$ and 78\% identical to their Ae. aegypti and C. quinquefasciatus homologs, respectively. Psor-21372 codes for a pacifastin homolog, which may be an $\mathrm{H}$ protein. A poorly expressed cystatin may also be an $\mathrm{H}$ protein, but tick salivary cystatins are secreted and poorly expressed and could have immunosuppressive function [51,52].

\section{Immunity-related proteins}

Lysozyme, gambicin, cecropin, and defensins were found among antimicrobial agents. Pathogen recognition proteins of the ML domain, Fred/ficolin, Gram negative binding, peptidoglycan recognition, leucine-rich, galectin, and C-type lectin families were identified. Of these, lysozyme was identified in gel fraction 19 by MS/MS.

\section{Yellow protein family}

The yellow gene in Drosophila is responsible for tanning of the cuticle, and the mosquito homolog was shown to have a dopachrome oxidase function $[53,54]$. This protein family is specific to insects, the royal jelly protein being a member of the superfamily [55]. Interestingly, sand flies-but no other insect sialotranscriptomeshave two members of this family recently shown to be a scavenger of serotonin [56-58]. The P. albipes sialotranscriptome revealed two members of this family, probably alleles, relatively well expressed, assembled with over $200 \times$ coverage. This is the first description of a yellow family member in mosquito sialotranscriptomes; however, these results derive from a high-coverage mosquito sialotranscriptome, and it may be possible that members of this family may be found in species previously studied if higher transcript coverage is attained.

\section{Mosquito-specific protein families}

$1,319,744$ reads (18\% of the total reads classified as $\mathrm{S}$ products) mapped to transcripts encoding proteins that can be classified according to their sequence similarity to 18 different protein families $(21.68 \%$ of the total $\mathrm{S}$ protein families described in this transcriptome) previously described as unique to mosquitoes, i.e., they are not recognized in any other organism apart from mosquitoes [24]. A total of $69.23 \%$ of these mosquitospecific contigs had their best matches originating from Aedes, followed by $8.15 \%$ best matching to Ochlerotatus, $6.52 \%$ to Culex, and $4.66 \%$ to Anopheles. A previous review of Nematocera sialomes [24] proposed that some of these mosquito-specific families appear to be spread in all mosquito genera (studied so far), while others show specific distributions to a certain mosquito subfamily and/or genus. Accordingly, we conceptually divided our discussion regarding the mosquito-specific protein families present in Psorophora sialomes into four groups: $i$ ) mosquito-specific protein families common to Culicines and Anophelines, ii) mosquito-specific protein families thus far found only in Culicines, iii) mosquito-specific protein families unique to Aedes/Ochlerotatus, and iv) mosquito-specific protein families unique to Culex.

\section{Mosquito-specific protein families common to Culicines and Anophelines}

Nine of the 12 protein families previously known as common to Culicine and Anopheline were described in the $P$. albipes transcriptome: the $\mathrm{HHH}$ peptide family, the $\mathrm{HHH}$ peptide family 2 , the mosquito basic tail family, the salivary protein 16 family, the Aedes/Anopheles darlingi 14-15 family, the gSG8 family, the Hyp6.2 family, the Aedes $62 \mathrm{kDa}$ family, and the Anopheline SG1 family. Although commonly found in mosquito SG transcriptome analyses, no member of these families has been functionally characterized so far. Moreover, studies based on RT-PCR have assigned to some of these family members a tissue and/or sex specificity in their expression that suggests a role in the physiology of Ae. albopictus SGs [24].

Among them, the $\mathrm{HHH}$ peptide family was previously suggested to play a role in antimicrobial defense because of its His richness as $\mathrm{Zn}$ ion chelators [24,59]. Here, this family was revealed as the fourth most abundantly expressed, with $7.65 \%$ of the total reads (Table 3). This family appears to be expanded in Psorophora, with a possible total of at least six genes (Figure 3). The abundant expression of this protein family suggests this protein as a good candidate for exposure marker to mosquito bites. Alignment of Psorophora transcripts 
Figure 2 Phylogram of the salivary serpins of Psorophora albipes. The bootstrapped (1,000 iterations) phylogram was obtained using the serpins from $P$. albipes and their best-matching proteins from the non-redundant database from NCBI. P. albipes proteins are recognized by the prefix Psor- and a red marker (red circle symbol). Other proteins are represented by the first three letters of the genus name, followed by the first three letters of the species name, followed by their gil accession number. The Aedes aegypti proteins identified as anti Xa anticlotting are marked with a blue symbol (blue reversed triangle symbol). The sole Lutzomyia longipalpis protein is identified by a green symbol (green circle symbol).The numbers at the nodes represent bootstrap support for 1,000 iterations using the neighbor-joining algorithm. The bar at the bottom indicates 50\% amino acid substitution. Roman numerals indicate individual clades with strong bootstrap support.

encode two HHH repeats separated by NGTS amino acids, while one repeat was seen in the homologs from Aedes, Ochlerotatus, and Culex (Figure 3A); 35\% to 55\% identity is observed to the Ae. aegypti and Ae. albopictus homologs. The phylogram obtained after alignment of all $\mathrm{HHH}$ peptide genes found in mosquitoes shows at least five distinct clades with strong bootstrap support (Figure 3C). Two clades contain solely Psorophora transcripts (in several subclades). The remaining clades are specific to Culex, An. darlingi, Ochlerotatus, and Aedes (Figure 3C).

Mosquito basic tail proteins contain a Lys dipeptide tail (Figure 3B) and have been suggested as binding to negatively charged phospholipids found in cell membranes such as in the surface of platelets [60]. They may also be associated with plasminogen activation [61,62]. In the Psorophora transcriptome, six contigs $(0.43 \%$ of the total contigs classified as $\mathrm{S}$ products) match mosquito basic tail peptides with $50 \%$ identity to Ae. albopictus family members (Additional file 1). Three tryptic peptides in our proteome analysis match contig Psor13880, which encodes for a member of this family. Phylogenetic analysis of the basic tail mosquito family supports divergence of Culicine salivary proteins from the Anopheline family members (Figure 3D) where Anopheline and Culicine proteins are grouped in distinct clades (Figure 3D). Although Anophelines lack the basic tail, they have a conserved backbone (Figure 3B). In the Culicine clade, we observe that all Psorophora proteins are isolated in a genus-specific branch, separated from the other Culicine proteins with strong bootstrap support (Figure 3D).

Family Hyp6.2, represented with three truncatedsequences, is approximately $45 \%$ identical to the homologs from Ochlerotatus (Additional file 1). Additionally, all the contigs found in P. albipes transcriptome from the mosquito-specific families $\mathrm{HHH}$ family-2, salivary protein 16 family, Aedes/An. darlingi family, gSG8 family, and Aedes $62-\mathrm{kDa}$ family have as their best matches 


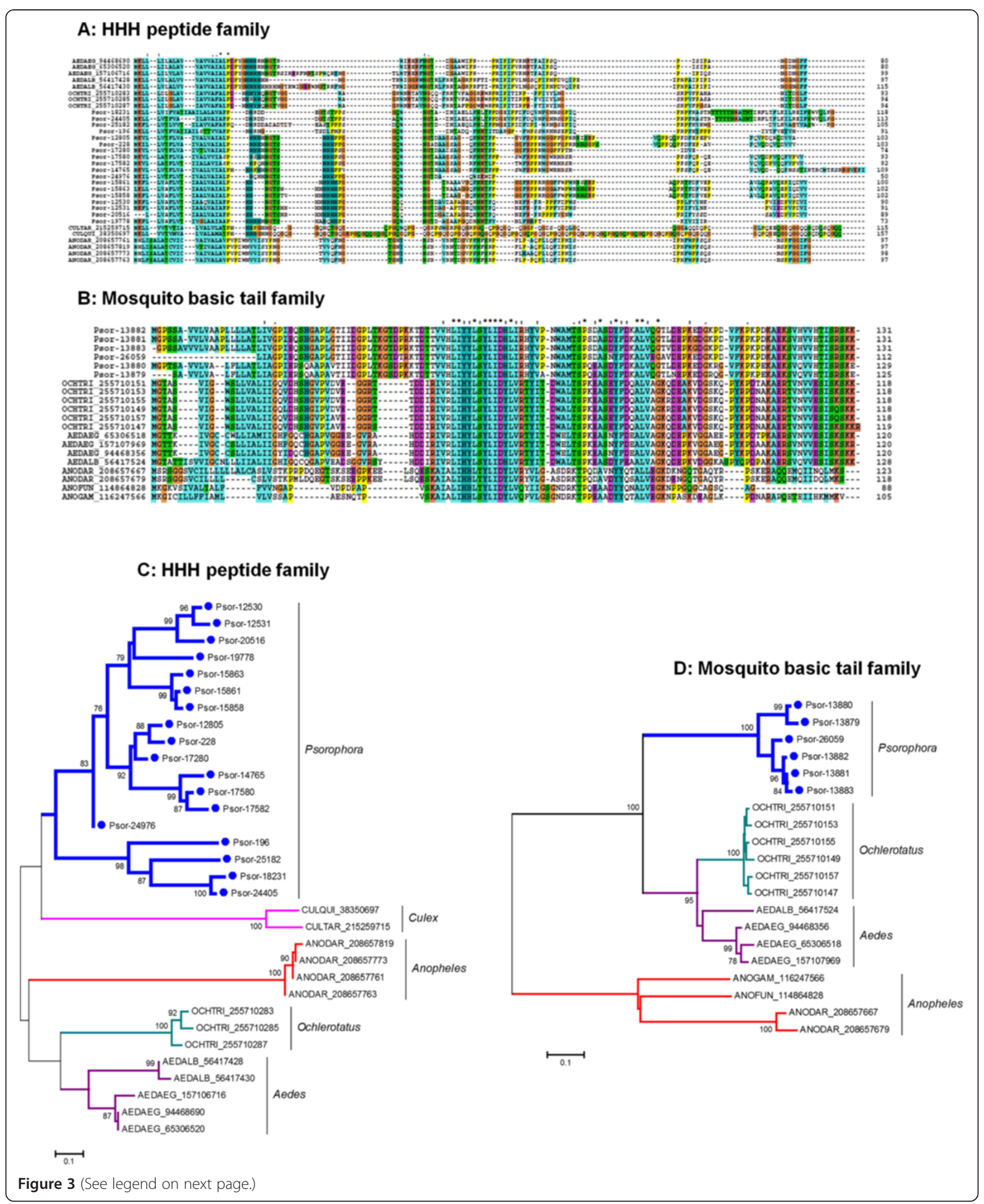


(See figure on previous page.)

Figure 3 Phylogram of salivary protein families derived from Psorophora albipes sialotranscriptome commonly found in Culicine and Anopheline mosquito sialotranscriptomes. A, C: HHH peptide family. B, D: Mosquito basic tail family. Clustal alignment (A and B) and dendrogram (C and D) of all HHH peptide family and mosquito basic tail family, respectively, derived from the Psorophora sialotranscriptome. The symbols above the alignment indicate $\left(^{*}\right)$ identical sites, (:) conserved sites, and (.) less-conserved sites. The phylogram derived from the alignment of Psorophora proteins (indicate by Psor- and its contig number) with their best matches in the non-redundant database. The three first letters indicate the genus name from which each protein originates, followed by the three first letters of the species name, followed by the NCBI accession number. The numbers on the tree bifurcations indicate the percentage of bootstrap support above $75 \%$. The scale bar at the bottom represents $10 \%$ amino acid substitution. Sequences were aligned by the ClustalW program, and the phylogram was made with the Mega package after 10,000 bootstraps with the neighbor-joining algorithm.

the homologs from Ae. aegypti, with identities varying from $80 \%$ to $42 \%$ (Additional file 1). Proteome analysis revealed tryptic peptides originating from Psorophora family members showing higher similarities to the Aedes 62-kDa family (Additional file 1).

\section{Mosquito-specific protein families thus far found only in Culicines}

To date, five protein families found in the P. albipes sialotranscriptome are unique to Culicines. Two of these (9.7-kDa and Hyp8.2 Culicine protein families) may play a role in blood feeding, as they are abundantly expressed in female Ae. albopictus SGs [63]. The 30.5$\mathrm{kDa}$ and 23.5-kDa protein families appear to be involved in mosquito sugar feeding due to their reported expression in male and female SGs [63]; however, the tissue specificity of the fifth protein family-namely, the GQrich Culicine family-is still unknown $[63,64]$. So far, no member from these families has been functionally characterized.

Two abundantly expressed families in our transcriptome analysis are represented by the $30.5-\mathrm{kDa}(4.35 \%$ of total reads encoding for S products) and Hyp8.2 Culicine families (1.30\% of total reads encoding for $S$ products). The first family was also within the 50 most-expressed families in this transcriptome (Table 3). Expression of these two families in Psorophora SGs was confirmed by our proteome analysis (Figure 1 and Table 4). Overall, they share 53\% amino acid identity with the family member from Ae. albopictus (Additional file 1). The Psorophora $9.7-\mathrm{kDa}$ and $23.5-\mathrm{kDa}$ families had $A e$. aegypti proteins as their best BLAST similarity matches; tryptic peptides were found in our proteome analysis identifying these family members. In contrast, members of the GQ-rich Culicine family revealed 58\% identity to its homologs from C. quinquefasciatus (Additional file 1).

Here we performed phylogenetic analysis of the 9.7$\mathrm{kDa}$ family (Figure 4A), the $30.5-\mathrm{kDa}$ family (Figure $4 \mathrm{~B}$ ), the $23.5-\mathrm{kDa}$ family (Figure $4 \mathrm{C}$ ), and GQ-rich family (Figure 4D). Overall, all four phylograms show Psorophora proteins phylogenetically far from Culex proteins. The phylogenetic tree of the 9.7-kDa family (Figure 4A) shows at least four different transcript clusters in
Psorophora (one cluster in the branch named Psorophora-I and three in Psorophora-II). Also, several gene duplications can be found in each cluster. This phylogeny shows that Aedes family members are closer to Psorophora family members, while Culex proteins appear as an outgroup (Figure 4A).

The phylogram of the $30.5-\mathrm{kDa}$ (Figure $4 \mathrm{~B}$ ) and 23.5$\mathrm{kDa}$ (Figure 4C) families confirm the same pattern seen for the $9.7-\mathrm{kDa}$ family (Figure 4A) in the sense that Psorophora proteins are grouped in the same clade with $A e$ des proteins (Figure $4 \mathrm{~A}-\mathrm{C}$ ). The GQ-rich family shows Psorophora members grouped within the same clade containing Ochlerotarus proteins (Figure 4D). Although previous studies using 18S rDNA sequence suggested Psorophora species as a sister group to Culex and/or a sister group to the Aedes/Ochlerotatus species [12,16], our results suggest-based on the composition of the salivary proteins-that Psorophora is much closer to Aedes than to Culex.

\section{Mosquito-specific protein families unique to Aedes/ Ochlerotatus mosquitoes}

Three protein families-Aedes $6.5-8.5-\mathrm{kDa}$ family (Figure 5A), Aedes W-rich peptides family (Figure 5B), and Aedes 34-kDa family (Figure 5C)-previously described as exclusive to Aedes/Ochlerotatus were found in the Psorophora genus. Previous studies showed that these families are female- and SG-specific [63,64], but their function still remains unknown. Alignment of the transcripts found in Psorophora encoding for Aedes 6.5-8.5-kDa (Figure 5A) and Aedes W-rich peptides (Figure 5B) families reveal higher identity in their amino acid sequences to Ae. albopictus (55\%) and to Ochlerotatus triseriatus (62\%), respectively (Additional file 1). Here, only the 34-kDa family was confirmed as present in the Psorophora SG proteome (fraction F14; Figure 1, Table 4). Alignments of 34-kDa family members showed 29-37\% identity to their homologous proteins from Aedes mosquitoes (Figure 5C and Additional file 1). The phylogram shows all Psorophora proteins of the $34-\mathrm{kDa}$ family grouped in the same clade, while the second clade of the phylogram contains all the Aedes/Ochlerotatus gene products (Figure 5C). 


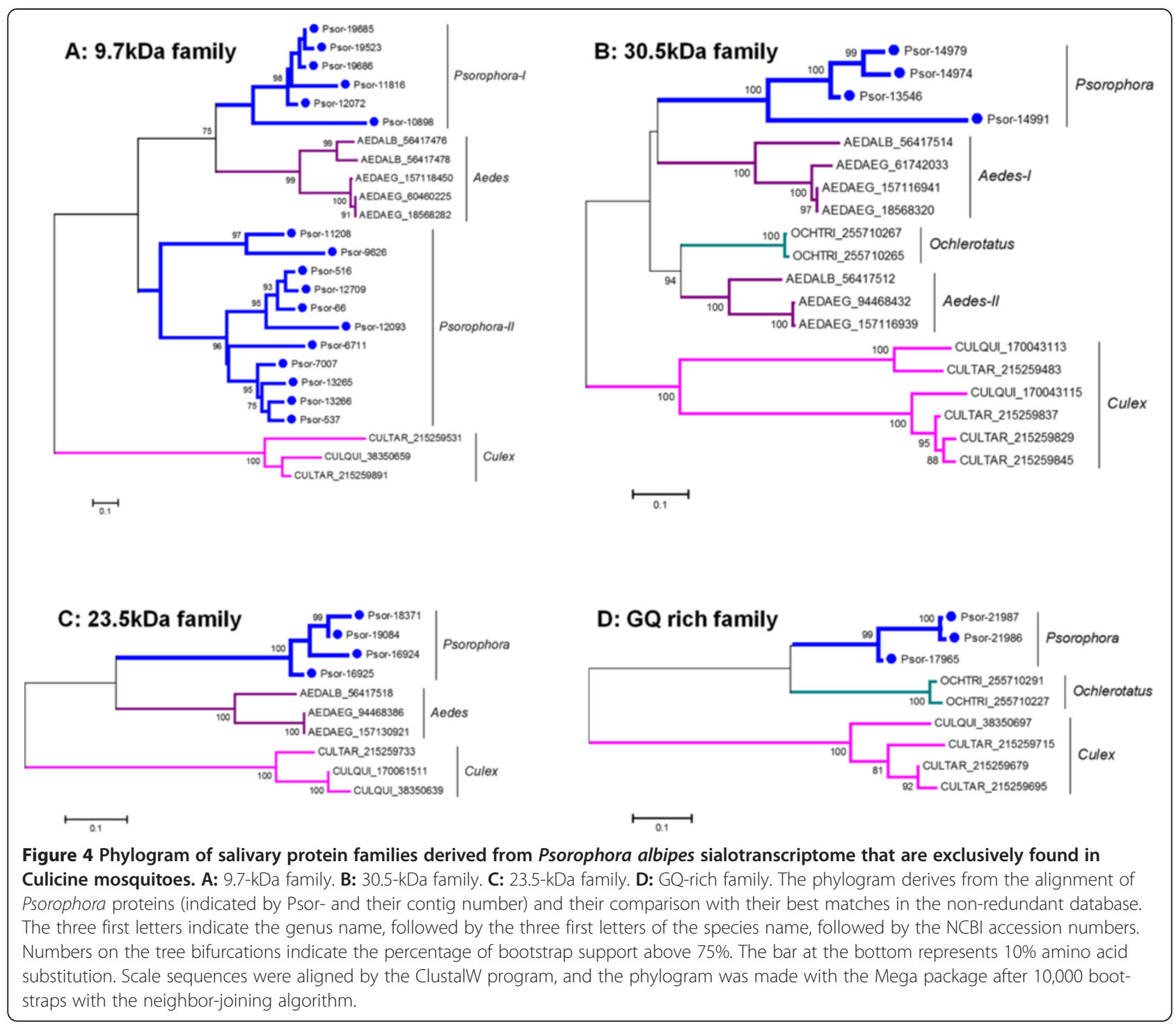

\section{Protein family so far found only in Culex}

The Culex W-rich protein (WRP)/16-kDa family is a salivary protein family so far uniquely found in Culex sialotranscriptomes, where nearly 20 genes coding for this family are known, subdivided into different subfamilies varying in their number of cysteine residues $[44,65]$. Although highly expressed and specific to Culex, the function of the WRP/16-kDa family remains still unclear. Here we report for the first time members of this family originating from a non-Culex mosquito. A total of 2,138 reads were found grouped into two contigs, Psor-32363 and Psor-32364, the latter being a truncated variant of the first with a few amino acid changes. The mature MW of the encoded polypeptides is approximately $24 \mathrm{kDa}$ with an estimated isoelectric point of 7.1 and amino acid sequences that are $\mathrm{W}$ rich (Additional file 1). Interestingly, the Psorophora protein best matches two putative Ae. aegypti proteins never previously described in sialotranscriptomes. Alignment of the $P$. albipes sequence with Aedes and selected Culex sequences shows three conserved tryptophan residues among a total of 8 identities and 22 similarities, with a total similarity of only $14 \%$ (Figure 6A). Phylogenetic analysis (Figure 6B) groups the Psorophora and Aedes sequences with $100 \%$ bootstrap support within a clade of four Culex proteins having 99\% bootstrap support (Clade III in Figure 6B). These results suggest that Culicines shared a common ancestor of a gene coding for this protein family that expanded in Culex but not in Aedes, indicating this family was not a Culex "invention." The Psorophora member of the family thus helped us to partially understand the evolution of this family in Culex by providing a link between Culex and Aedes sequences. 


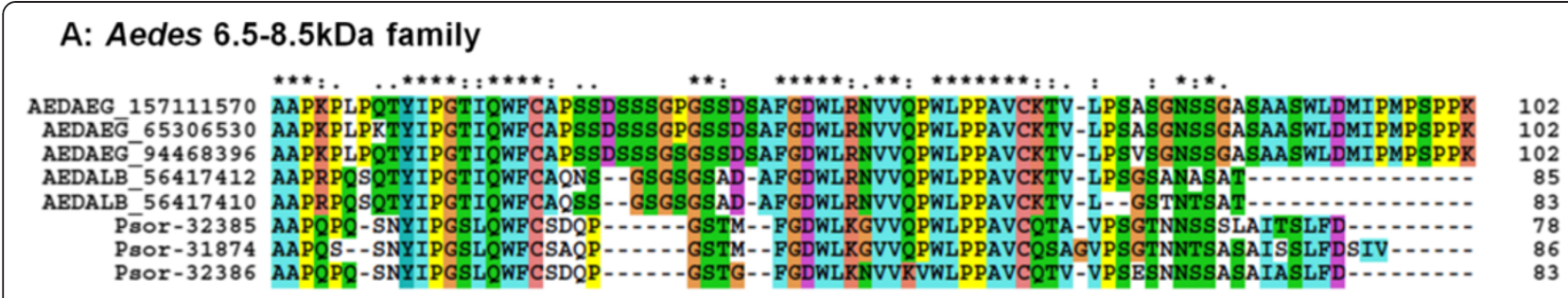

\section{B: Aedes W rich peptides family}

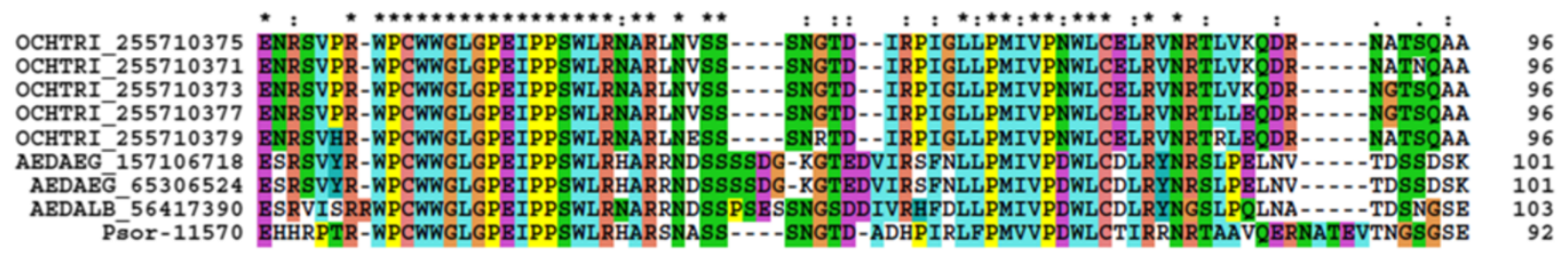

\section{C: $34 \mathrm{kDa}$ Aedes family}
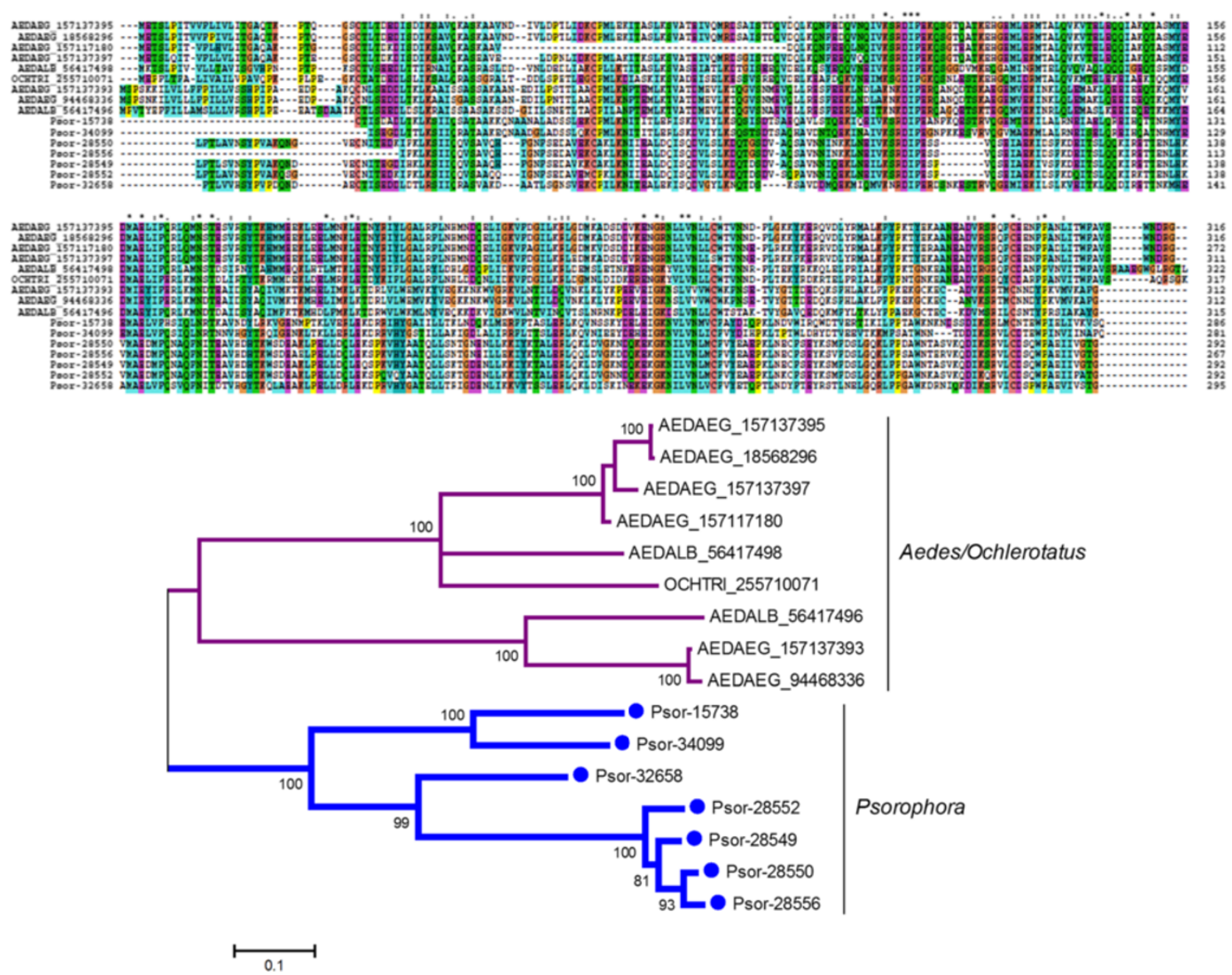

Figure 5 Phylogenetic analyses of salivary Psorophora protein families previously found exclusively in Aedes/Ochlerotatus mosquitoes. Clustal alignment of all Aedes 6.5-8.5-kDa proteins (A) and Aedes W-rich peptides (B) derived from Psorophora sialotranscriptome. Symbols above the alignment indicate $\left(^{*}\right)$ identical sites, (:) conserved sites, and (.) less-conserved sites. Aedes $34-\mathrm{kDa}$ family alignment and bootstrapped phylogram (C). The numbers on the tree bifurcations indicate the percentage bootstrap support above $75 \%$. The scale bar at the bottom represents 10\% amino acid substitution. Sequences were aligned by the ClustalW program, and the dendrogram was made with the Mega package after 10,000 bootstraps with the neighbor-joining algorithm. 


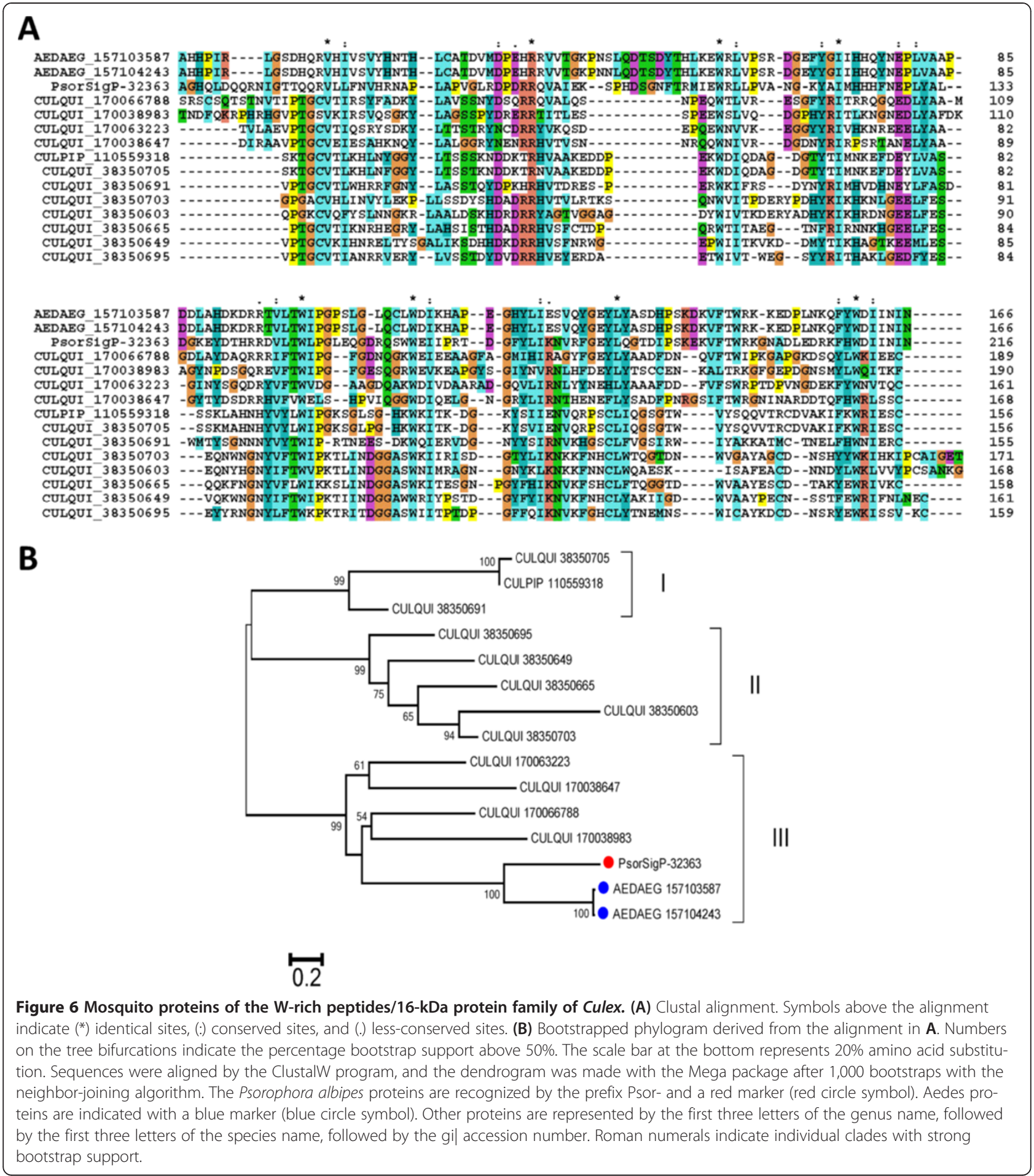

\section{Other putative secreted proteins}

Two putative $\mathrm{S}$ protein sequences match black fly proteins previously thought to be unique to Simulium sialomes. Three previously thought to be orphan proteins of Aedes and Ochlerotatus (Aedes 7-kDa and 5-kDa families and Ochlerotatus OT-19 family) were deorphanized. Eight novel salivary protein families were found in the
Psorophora sialotranscriptome, four of which appear unique to Psorophora, while the others have matches to mosquito hypothetical proteins not previously described in sialotranscriptomes.

We additionally identified 372 transcripts sequences encoding for secreted polypeptides, most of which have no relevant matches to any sequence deposited thus far 
in the NR database. Two of these were identified by proteome analysis. All details of these proteins are in the hyperlinked Excel spreadsheet available in Additional file 1.

\section{P. albipes similarities to other mosquito species}

The availability of the genomes of Ae. aegypti, C. quinquefasciatus, and Anopheles gambiae [66-68] allows for comparisons of the protein sequences of Psorophora to those deducted from the three mosquito genomes. We have determined (Additional file 1) the BLAST score ratios of each protein for the three genomes by dividing the BLAST score found for the blastp result against one of the three mosquito proteomes by the BLAST score of the Psorophora protein blasted against itself [39]. The comparisons indicate that Aedes is the closest related mosquito to Psorophora, followed by Culex and Anopheles (Figure 7). It also shows that the $\mathrm{S}$ class of proteins has the lowest ratio of all, while those for proteasome machinery, nuclear regulation, and cytoskeletal are among the most conserved (Figure 7 ). In the $\mathrm{S}$ class computed above, those 372 proteins indicated as "Other putative secreted peptides" were not included, as they are of uncertain nature and would further decrease the score ratios. This divergence of salivary proteins in mosquitoes has been previously reported for other taxa $[22,24,63-65,69-71]$.

\section{Polymorphism of $P$. albipes coding sequences inferred} from the RNAseq data

RNAseq data produces high contig coverage. In our CDS set, 1,822 had average coverage of 100 or larger per nucleotide site, allowing reliable identification of SNPs using the tools BWA and Samtools (see Methods). From this CDS set we excluded the 372 proteins indicated in the previous section, plus all of the unknown class, and all CDS having a similar protein sequence with $>95 \%$ similarity (to avoid overrepresentation of alleles), producing a set of $1,100 \mathrm{CDS}$. When comparing the number of synonymous sites per 100 codons among different functional classes, the protein syntheses and secreted classes have the smallest value, while the proteasome and immune categories have the highest (Figure 8A and Table 5). When the values of the number of non-

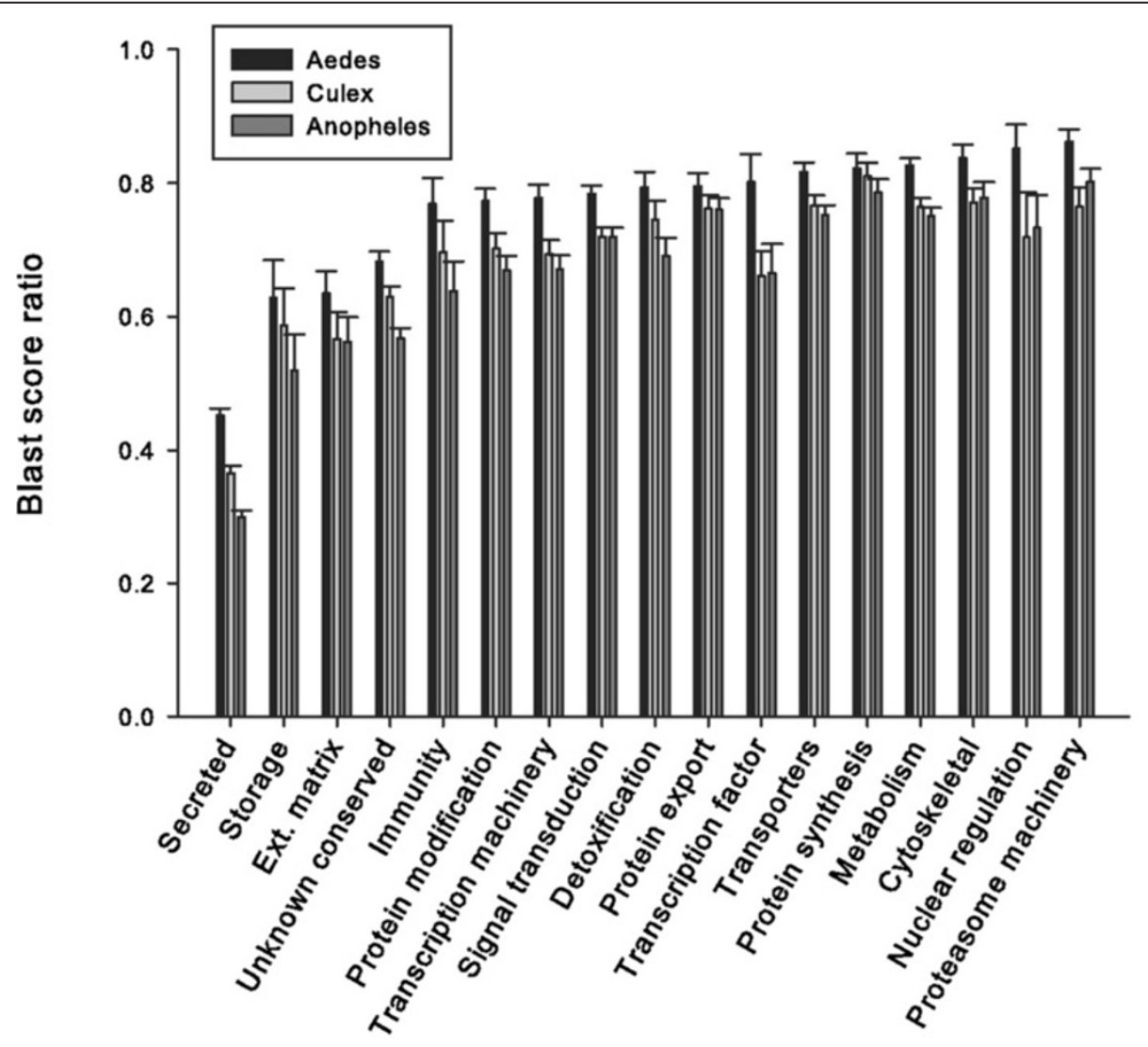

Figure 7 Comparison of Psorophora albipes protein sequences to those of Aedes aegypti (black square symbol), Culex quinquefasciatus (dark gray symbol), and Anopheles gambiae (SlateGray square symbol) by blastp score ratio. The bars and lines represent the average ratio and standard error calculated by dividing the score of the best-matching mosquito protein and the self-score of the protein for the functional categories indicated in the abscissa. For details, see text. 

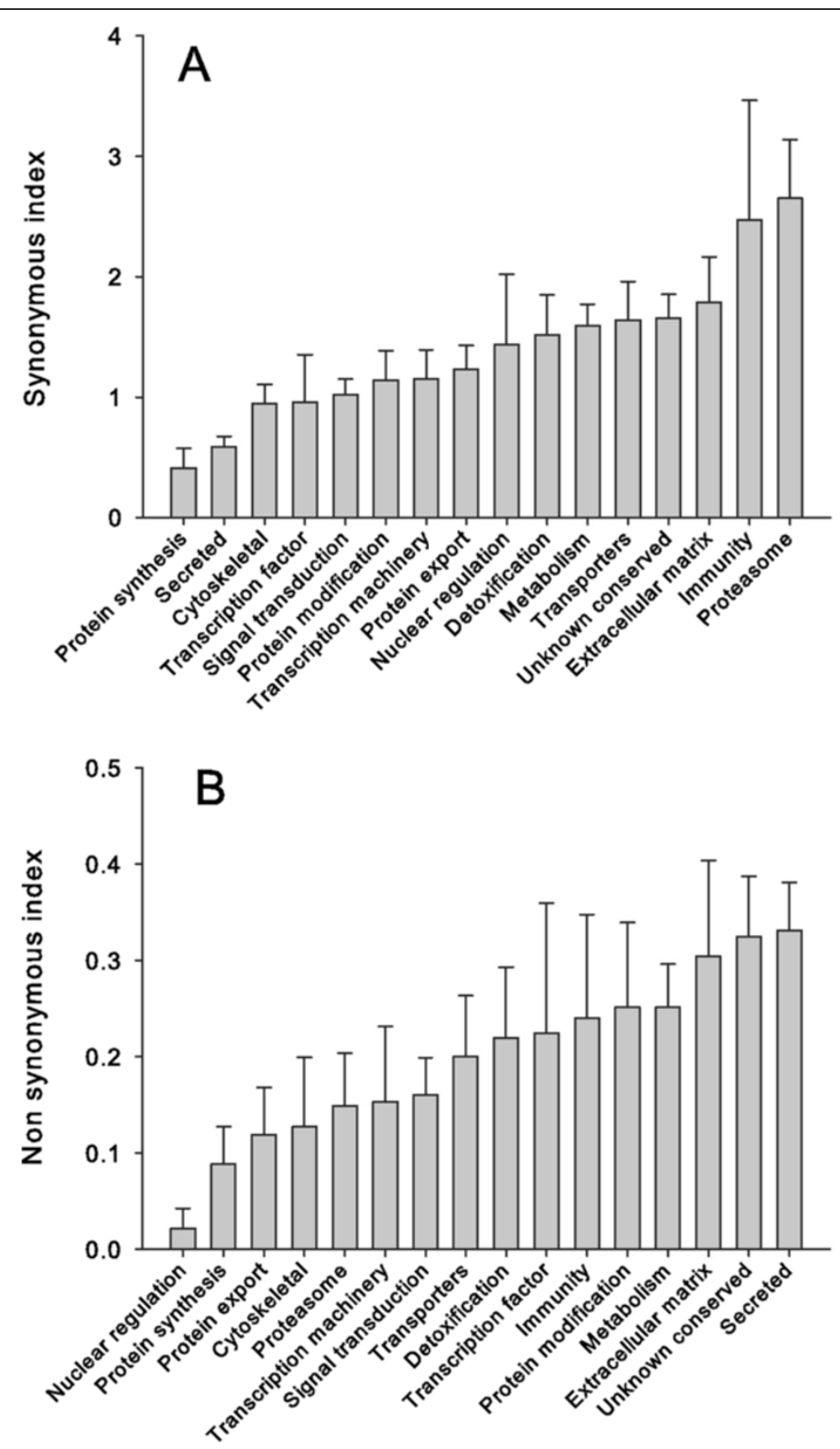

Figure 8 Number of polymorphic sites per 100 codons in Psorophora albipes proteins. Bars represent the average and standard errors of synonymous (A) and non-synonymous (B) sites per 100 codons in the indicated functional categories.

synonymous SNPs are compared, the figure reverses (Figure $8 \mathrm{~B}$ ), the secreted category having the highest value, to near 0.33 per 100 codons (Table 5 ). The overall non-synonymous to synonymous rate also shows the secreted class to have the highest ratio (Table 5). This increased non-synonymous polymorphism is not an artifact resulting of increased read coverage of the contigs of the secreted class because the protein synthesis class of contigs has an even higher read coverage but has the second smallest non-synonymous polymorphism index. It is possible that this high value of nonsynonymous polymorphism observed for the secreted class may result from chimeric assembly of coding sequences originating from multiple recently duplicated genes coding for very similar proteins. At any rate, this high polymorphism may underlie the mechanisms leading to accelerated evolution of salivary proteins observed in bloodsucking arthropods. 
Table 5 Psorophora albipes polymorphisms detected on a set of 1,100 coding sequences of 16 functional classes

\begin{tabular}{|c|c|c|c|c|c|c|c|c|}
\hline Class & Average (Syn /Codon) x $100^{1}$ & SE & Average (NS /codon) $\times 100^{2}$ & SE & NS/Syn & Average coverage $^{3}$ & SE & $\mathrm{N}$ \\
\hline Nuclear regulation & 1.4343 & 0.5854 & 0.0217 & 0.0207 & 0.0152 & 278.6 & 48.3 & 11 \\
\hline Protein synthesis & 0.4095 & 0.1637 & 0.0885 & 0.0389 & 0.2161 & 2981.7 & 243.9 & 96 \\
\hline Protein export & 1.2332 & 0.1954 & 0.1188 & 0.0491 & 0.0963 & 340.0 & 34.0 & 65 \\
\hline Cytoskeletal & 0.9455 & 0.1606 & 0.1271 & 0.0722 & 0.1344 & 322.5 & 48.0 & 54 \\
\hline Proteasome & 2.6511 & 0.4884 & 0.1487 & 0.0550 & 0.0561 & 189.0 & 20.4 & 35 \\
\hline Transcription & 1.1524 & 0.2376 & 0.1531 & 0.0785 & 0.1329 & 410.2 & 99.3 & 47 \\
\hline Signal transduction & 1.0220 & 0.1283 & 0.1604 & 0.0385 & 0.1570 & 365.9 & 69.9 & 143 \\
\hline Transporters & 1.6399 & 0.3186 & 0.1997 & 0.0638 & 0.1218 & 400.2 & 61.0 & 89 \\
\hline Detoxification & 1.5145 & 0.3318 & 0.2194 & 0.0739 & 0.1448 & 198.5 & 31.2 & 16 \\
\hline Transcription factor & 0.9573 & 0.3958 & 0.2243 & 0.1351 & 0.2343 & 237.2 & 30.2 & 12 \\
\hline Immunity & 2.4690 & 0.9928 & 0.2398 & 0.1077 & 0.0971 & 224.7 & 47.6 & 11 \\
\hline Protein modification & 1.1421 & 0.2421 & 0.2514 & 0.0877 & 0.2201 & 370.1 & 86.2 & 56 \\
\hline Metabolism & 1.5898 & 0.1807 & 0.2515 & 0.0447 & 0.1582 & 389.2 & 72.1 & 147 \\
\hline Extracellular matrix & 1.7871 & 0.3776 & 0.3044 & 0.0994 & 0.1703 & 280.6 & 39.9 & 29 \\
\hline Unknown conserved & 1.6564 & 0.1961 & 0.3244 & 0.0626 & 0.1958 & 372.9 & 44.6 & 127 \\
\hline Secreted & 0.5885 & 0.0849 & 0.3308 & 0.0498 & 0.5621 & 2729.7 & 288.8 & 334 \\
\hline Total & & & & & & & & 1100 \\
\hline
\end{tabular}

${ }^{1}$ Number of synonymous polymorphism per 100 codons.

${ }^{2}$ Number of non-synonymous polymorphism per 100 codons.

${ }^{3}$ Average read coverage of coding sequences.

\section{Conclusions}

The sialotranscriptome of $P$. albipes as described here is the first-or among the first-to use solely Illumina sequences for its assembly, in the absence of a reference genome. Over 3,000 coding sequences were recovered, 1,790 of which were submitted to GenBank. This is also the first transcriptome of a member of the Psorophora genus. As expected, the protein sequences presented more similarities to Aedes, followed by Culex and Anopheles proteins. Despite this more Aedine nature, $P$. albipes presented some Culex characters-such as the presence of endonuclease and hyaluronidase-common in sand flies and black flies but so far uniquely found in Culex. A Psorophora protein similar to the WRP/16-kDa family also unique so far to Culex allowed the discovery of a "missing link" between this Culex family and hypothetical Ae. aegypti proteins, indicating this gene family is ancestral in all Culicines but poorly or not expressed in Aedes SGs. Orphan protein families from Aedes and Ochlerotatus were deorphanized, and several new families of proteins were identified, four of which appear unique to Psorophora, supporting the idea that sialotranscriptomes of new bloodsucking genera yield at least two novel protein families [72]. However, these novel sequences may result from misassemblies or chymeras. Further sequencing of other Psorophora species may clarify this area. Unique to Psorophora is also the finding of SMase, not previously found in mosquito sialomes. Because the sample derived from 50 field-collected mosquitoes, we also were able to derive an estimate of SNPs and the rate of synonymous and non-synonymous mutations in this data set.

\section{Availability of supporting data}

All data from the transcriptome and proteome analysis of $P$. albipes SGs are disclosed in Additional file 1, a hyperlinked Excel spreadsheet available at http://exon. niaid.nih.gov/transcriptome/Psorophora_albipes/Pso-s2web.xlsx. Raw reads were deposited in the SRA of the NCBI under bioproject numbers PRJNA208524 and 208958 and raw data file SRR908278. One thousand seven hundred and ninety coding sequences have been publicly deposited in the Transcriptome Shotgun Assembly project at DDBJ/EMBL/GenBank under accession GALA00000000. The version described in this paper is the first version, GALA01000000, ranging from GALA01000001 to GALA01001790.

\section{Additional files}

Additional file 1: Hyperlinked Excel spreadsheet with protein coding sequences and added information.

Additional file 2: Assembly information.

\section{Abbreviations}

ABySS: Assembly by short sequences software; bcftools: Binary call format tools; CDS: Coding sequences; H: Housekeeping proteins; MS: Mass spectrometry; MS/MS: Tandem MS; MW: Molecular weight; NCBI: National Center for Biotechnology Information; NGS: Next-generation sequencing; 
NISC: NIH Intramural Sequencing Center; S: Secreted proteins; samtools: Sequence alignment/map tools; SG: Salivary gland; SMase: Sphingomyelin phosphodiesterase; SNP: Single-nucleotide polymorphism; SRA: Sequence read archives; U: Proteins of unknown function; WRP: W-rich protein.

\section{Competing interests}

The authors declare that they have no competing interests.

\section{Authors' contributions}

ACC, EC, and JMCR contributed to experimental design, bioinformatics analysis, and writing of the manuscript. CMRV, FACP, and JFM contributed to insect collection, dissections, and taxonomic identification of mosquitoes. All authors read and approved the final manuscript.

\section{Acknowledgments}

This work was supported by the Intramural Research Program of the Division of Intramural Research, National Institute of Allergy and Infectious Diseases, National Institutes of Health and by Fundação Oswaldo Cruz (Fiocruz) represented by Instituto Leônidas e Maria Deane (ILMD). We also thank the PAPES V program support FIOCRUZ/CNPq. We are grateful to Dr. Michalis Kotsyfakis for the critical reading of the manuscript and to Brenda Rae Marshall, DPSS, NIAID, for editing assistance. In addition, we thank Dr. Roberto Rocha (Fiocruz/Amazonia/ Brazil) for his support. Because JMCR, EC, and ACC are government employees and this is a government work, the work is in the public domain in the United States. Notwithstanding any other agreements, the $\mathrm{NIH}$ reserves the right to provide the work to PubMedCentral for display and use by the public, and PubMedCentral may tag or modify the work consistent with its customary practices. You can establish rights outside of the U.S. subject to a government use license.

\section{Author details}

${ }^{1}$ Laboratory of Malaria and Vector Research, National Institute of Allergy and Infectious Diseases, National Institutes of Health, Rockville, MD, USA. Biodiversity Laboratory, Instituto Leônidas e Maria Deane/Fiocruz, Manaus, Amazonas, Brazil. ${ }^{3}$ Entomology Laboratory, Fiocruz Rondônia, Porto Velho, Rondônia, Brazil.

Received: 26 July 2013 Accepted: 4 December 2013 Published: 13 December 2013

\section{References}

1. Molaei G, Andreadis T, Armstrong P, Diuk-Wasser M: Host-feeding patterns of potential mosquito vectors in Connecticut, USA: Molecular analysis of bloodmeals from 23 species of Aedes, Anopheles, Culex, Coquillettidia, Psorophora and Uranotaenia. J Med Entomol 2008, 45(6):1143-1151.

2. Dos Santos Silva J, Alencar J, JM C, Seixas-Lorosa E, Guimaraes A: Feeding patterns of mosquitoes (Diptera:Culicidae) in six Brazilian environmental preservation areas. J Vector Ecol 2012, 37(2):342-350.

3. Turell M, Barth J, Coleman R: Potential for Central American mosquitoes to transmit epizootic and enzootic strains of Venezuelan equine encephalitis virus. J Am Mosq Control Assoc 1999, 15(3):295-298.

4. Turell M, Jones J, Sardelis M, Dohm D, Coleman R, Watts D, Fernandez R, Calampa C, Klein T: Vector competence of Peruvian mosquitoes (Diptera: Culicidae) for epizootic and enzootic strains of Venezuelan equine encephalomyelitis virus. J Med Entomol 2000, 37(6):835-839.

5. Turell M, Dohm D, Fernandez R, Calampa C, O'Guinn ML: Vector competence of Peruvian mosquitoes (Diptera:Culicidae) for a subtype IIIC virus in the Venezuelan equine encephalomyelitis complex isolated from mosquitoes captured in Peru. J Am Mosq Control Assoc 2006, 22(1):70-75

6. Unlu I, Kramer W, Roy A, LD F: Detection of West Nile virus RNA in mosquitoes and identification of mosquito blood meals collected at alligator farms in Louisiana. J Med Entomol 2010, 47(4):625-633.

7. Pitzer J, Byford R, Vuong H, Steiner R, RJ C, Caccamise D: Potential vectors of West Nile virus in a semiarid environment: Dona Ana County, New mexico. J Med Entomol 2009, 46(6):1474-1482.

8. Moreno E, Rocco I, Bergo E, Brasil R, Siciliano M, Suzuki A, Silveira V, Bisordi I, Souza R, Group YFW: Reemergence of yellow fever: detection of transmission in the State of Sao Paulo, Brazil, 2008. Rev Soc Bras Med Trop 2011, 44(3):290-296.
9. Laporta G, Ribeiro M, Ramos D, Sallum M: Spatial distribution of arboviral mosquito vectors (Diptera, Culicidae) in Vale do Ribeira in the South-eastern Brazilian Atlantic Forest. Cad Saude Publica 2012, 28(2):229-238.

10. Ross H: Conflict with Culex. Mosq News 1951, 11:128-132.

11. Besansky N, Fahey G: Utility of the white gene in estimating phylogenetic relationships among mosquitoes (Diptera: Culicidae). Mol Biol Evol 1997, 14:442-454.

12. Forattini O: Culicidologia medica, vol. 2. São Paulo: Editora da Universidade de São Paulo - EDUSP; 2002.

13. Isoe J: Comparative analysis of the vitellogenin genes of the Culicidae. Tucson, AZ: University of Arizona; 2000.

14. Savage $H$, Strickman D: The genus and subgenus categories within Culicidae and placement of Ochlerotatus as a subgenus of Aedes. J Am Mosa Control Assoc 2004, 20:208-214.

15. Reinert J, Harbach R, Kitching I: Phylogeny and classification of Aedini (Diptera:Culicidae), based on morphological characters of all life stages. Zool J Linn Soc 2004, 142:289-368.

16. Shepard JJ, Andreadis TG, Vossbrinck CR: Molecular phylogeny and evolutionary relationships among mosquitoes (Diptera: Culicidae) from the northeastern United States based on small subunit ribosomal DNA (18S rDNA) sequences. J Med Entomol 2006, 43(3):443-454

17. Ribeiro JMC: Role of arthropod saliva in blood feeding. Ann Rev Entomol 1987, 32:463-478.

18. Camez A, Dupuy E, Bellucci S, Calvo F, Bryckaert MC: Human platelet-tumor cell interactions vary with the tumor cell lines. Invasion-Metastasis 1986, 6:321-334.

19. Calvo E, Mans BJ, Ribeiro JM, Andersen JF: Multifunctionality and mechanism of ligand binding in a mosquito antiinflammatory protein. Proc Natl Acad Sci USA 2009, 106(10):3728-3733.

20. Calvo E, Mizurini D, Sa-Nunes A, Ribeiro JM, Andersen J, Mans B, Monteiro R, Kotsyfakis M, Francischetti I: Alboserpin, a factor Xa inhibitor from the mosquito vector of yellow fever, binds heparin and membrane phospholipids and exhibits antithrombotic activity. J Biol Chem 2011, 286:27998-28010

21. Calvo E, Tokusamu F, Mizurini D, McPhie P, Narum D, Ribeiro JM, Monteiro R, Francischetti I: Aegyptin displays high-affinity for the von Willebrand factor binding site (QGQOGVMGF) in collagen and inhibits carotid thrombus formation in vivo. FEBS J 2010, 277(2):413-427.

22. Calvo E, Pham VM, Marinotti O, Andersen JF, Ribeiro JM: The salivary gland transcriptome of the neotropical malaria vector Anopheles darlingi reveals accelerated evolution of genes relevant to hematophagy. BMC Genomics 2009, 10:57.

23. Ribeiro JM, Francischetti IM: Role of arthropod saliva in blood feeding: sialome and post-sialome perspectives. Annu Rev Entomol 2003, 48:73-88.

24. Ribeiro JM, Mans BJ, Arca B: An insight into the sialome of blood-feeding Nematocera. Insect Biochem Mol Biol 2010, 40(11):767-784.

25. Valenzuela JG: High-throughput approaches to study salivary proteins and genes from vectors of disease. Insect Biochem Mol Biol 2002, 32(10):1199-1209.

26. Consoli RAGB, de Oliveira RL: Principais mosquitos de importancia sanitaria no Brasil. Rio de Janeiro: Editora Fiocruz; 1994.

27. Birol I, Jackman SD, Nielsen CB, Qian JQ, Varhol R, Stazyk G, Morin RD, Zhao $Y$, Hirst M, Schein JE, et al: De novo transcriptome assembly with ABySS. Bioinformatics (Oxford, England) 2009, 25(21):2872-2877.

28. Simpson JT, Wong K, Jackman SD, Schein JE, Jones SJ, Birol I: ABySS: a parallel assembler for short read sequence data. Genome Res 2009, 19(6):1117-1123.

29. Zhao QY, Wang Y, Kong YM, Luo D, Li X, Hao P: Optimizing de novo transcriptome assembly from short-read RNA-Seq data: a comparative study. BMC Bioinformatics 2011, 12(Suppl 14):S2.

30. Grabherr MG, Haas BJ, Yassour M, Levin JZ, Thompson DA, Amit I, Adiconis $X$, Fan L, Raychowdhury R, Zeng $Q$, et al: Full-length transcriptome assembly from RNA-Seq data without a reference genome. Nat Biotechnol 2011, 29(7):644-652.

31. Karim S, Singh $P$, Ribeiro JM: A deep insight into the sialotranscriptome of the Gulf Coast tick, Amblyomma maculatum. PLOS ONE 2011 6(12):e28525

32. Nielsen $H$, Brunak $S$, von Heijne $G$ : Machine learning approaches for the prediction of signal peptides and other protein sorting signals. Protein Eng 1999, 12(1):3-9.

33. Duckert $P$, Brunak S, Blom N: Prediction of proprotein convertase cleavage sites. Protein Eng Des Sel 2004, 17(1):107-112. 
34. Sonnhammer EL, von Heijne G, Krogh A: A hidden Markov model for predicting transmembrane helices in protein sequences. Proc Int Conf Intell Syst Mol Biol 1998, 6:175-182.

35. Julenius K, Molgaard A, Gupta R, Brunak S: Prediction, conservation analysis, and structural characterization of mammalian mucin-type O-glycosylation sites. Glycobiology 2005, 15(2):153-164.

36. Altschul SF, Madden TL, Schaffer AA, Zhang J, Zhang Z, Miller W, Lipman DJ: Gapped BLAST and PSI-BLAST: a new generation of protein database search programs. Nucleic Acids Res 1997, 25(17):3389-3402.

37. Thompson JD, Gibson TJ, Plewniak F, Jeanmougin F, Higgins DG: The CLUSTAL_X windows interface: flexible strategies for multiple sequence alignment aided by quality analysis tools. Nucleic Acids Res 1997, 25(24):4876-4882.

38. Kumar S, Tamura K, Nei M: MEGA3: Integrated software for Molecular Evolutionary Genetics Analysis and sequence alignment. Brief Bioinform 2004, 5(2):150-163.

39. Rasko DA, Myers GS, Ravel J: Visualization of comparative genomic analyses by BLAST score ratio. BMC Bioinformatics 2005, 6:2.

40. Li H, Durbin R: Fast and accurate long-read alignment with BurrowsWheeler transform. Bioinformatics (Oxford, England) 2010, 26(5):589-595.

41. Li H, Handsaker B, Wysoker A, Fennell T, Ruan J, Homer N, Marth G, Abecasis G, Durbin R, Genome Project Data Processing S: The sequence alignment/ map format and SAMtools. Bioinformatics (Oxford, England) 2009, 25(16):2078-2079.

42. Chagas AC, Calvo E, Pimenta PF, Ribeiro JM: An insight into the sialome of Simulium guianense (DIPTERA:SIMulIIDAE), the main vector of River Blindness Disease in Brazil. BMC Genomics 2011, 12:612.

43. Wasinpiyamongkol L, Patramool S, Luplertlop N, Surasombatpattana P, Doucoure S, Mouchet F, Seveno M, Remoue F, Demettre E, Brizard J, et al: Blood-feeding and immunogenic Aedes aegypti saliva proteins. Proteomics 2010, 10:1906-1916.

44. Ribeiro JM, Charlab R, Pham VM, Garfield M, Valenzuela JG: An insight into the salivary transcriptome and proteome of the adult female mosquito Culex pipiens quinquefasciatus. Insect Biochem Mol Biol 2004, 34(6):543-563.

45. Wartha F, Beiter K, Normark S, Henriques-Normark B: Neutrophil extracellular traps: casting the NET over pathogenesis. Curr Opin Microbiol 2007, 10(1):52-56

46. Hannun Y, Obeid L: The Ceramide-centric universe of lipid-mediated cell regulation: stress encounters of the lipid kind. J Biol Chem 2002, 277(29):25847-25850.

47. Stark KR, James AA: Isolation and characterization of the gene encoding a novel factor Xa-directed anticoagulant from the yellow fever mosquito, Aedes aegypti. J Biol Chem 1998, 273(33):20802-20809.

48. Francischetti IM, Valenzuela JG, Ribeiro JM: Anophelin: kinetics and mechanism of thrombin inhibition. Biochemistry 1999, 38(50):16678-16685.

49. Valenzuela JG, Francischetti IM, Ribeiro JM: Purification, cloning, and synthesis of a novel salivary anti-thrombin from the mosquito Anopheles albimanus. Biochemistry 1999, 38(34):11209-11215.

50. Watanabe RM, Soares TS, Morais-Zani K, Tanaka-Azevedo AM, Maciel C Capurro ML, Torquato RJ, Tanaka AS: A novel trypsin Kazal-type inhibitor from Aedes aegypti with thrombin coagulant inhibitory activity. Biochimie 2010, 92(8):933-939.

51. Kotsyfakis M, Anderson JM, Andersen JF, Calvo E, Francischetti IM, Mather TN, Valenzuela JG, Ribeiro JM: Cutting edge: Immunity against a "silent" salivary antigen of the Lyme vector Ixodes scapularis impairs its ability to feed. J Immunol 2008, 181(8):5209-5212.

52. Kotsyfakis M, Sa-Nunes A, Francischetti IM, Mather TN, Andersen JF, Ribeiro $J M$ : Antiinflammatory and immunosuppressive activity of sialostatin L, a salivary cystatin from the tick Ixodes scapularis. J Biol Chem 2006, 281(36):26298-26307.

53. Han Q, Fang J, Ding H, Johnson JK, Christensen BM, Li J: Identification of Drosophila melanogaster yellow-f and yellow- $\mathrm{f} 2$ proteins as dopachromeconversion enzymes. Biochem J 2002, 368(Pt 1):333-340.

54. Johnson JK, Li J, Christensen BM: Cloning and characterization of a dopachrome conversion enzyme from the yellow fever mosquito, Aedes aegypti. Insect Biochem Mol Biol 2001, 31(11):1125-1135.

55. Albert S, Bhattacharya D, Klaudiny J, Schmitzova J, Simuth J: The family of major royal jelly proteins and its evolution. J Mol Evol 1999, 49(2):290-297.

56. Charlab R, Valenzuela JG, Rowton ED, Ribeiro JM: Toward an understanding of the biochemical and pharmacological complexity of the saliva of a hematophagous sand fly Lutzomyia longipalpis. Proc Natl Acad Sci USA 1999, 96(26):15155-15160.

57. Valenzuela JG, Garfield M, Rowton ED, Pham VM: Identification of the most abundant secreted proteins from the salivary glands of the sand fly Lutzomyia longipalpis, vector of Leishmania chagasi. J Exp Biol 2004, 207(Pt 21):3717-3729.

58. Xu X, Oliveira F, Chang BW, Collin N, Gomes R, Teixeira C, Reynoso D, My Pham V, Elnaiem DE, Kamhawi S, et al: Structure and function of a "yellow" protein from saliva of the sand fly Lutzomyia longipalpis that confers protective immunity against Leishmania major infection. J Biol Chem 2011, 286(37):32383-32393.

59. Loomans HJ, Hahn BL, Li QQ, Phadnis SH, Sohnle PG: Histidine-based zincbinding sequences and the antimicrobial activity of calprotectin. J Infect Dis 1998, 177(3):812-814

60. Andersen JF, Gudderra NP, Francischetti IM, Valenzuela JG, Ribeiro JM: Recognition of anionic phospholipid membranes by an antihemostatic protein from a blood-feeding insect. Biochemistry 2004, 43(22):6987-6994.

61. Castellino FJ, McCance SG: The kringle domains of human plasminogen. Ciba Found Symp 1997, 212:46-60. discussion 60-45.

62. Mosesson MW, Siebenlist KR, Meh DA: The structure and biological features of fibrinogen and fibrin. Ann N Y Acad Sci 2001, 936:11-30.

63. Arca B, Lombardo F, Francischetti IM, Pham VM, Mestres-Simon M, Andersen $J F$, Ribeiro JM: An insight into the sialome of the adult female mosquito Aedes albopictus. Insect Biochem Mol Biol 2007, 37(2):107-127.

64. Ribeiro JM, Arca B, Lombardo F, Calvo E, Phan VM, Chandra PK, Wikel SK: An annotated catalogue of salivary gland transcripts in the adult female mosquito, Aedes aegypti. BMC Genomics 2007, 8(1):6

65. Calvo E, Sanchez-Vargas I, Favreau AJ, Barbian KD, Pham VM, Olson KE, Ribeiro JM: An insight into the sialotranscriptome of the West Nile mosquito vector, Culex tarsalis. BMC Genomics 2010, 11(1):51.

66. Arensburger P, Megy K, Waterhouse RM, Abrudan J, Amedeo P, Antelo B, Bartholomay L, Bidwell S, Caler E, Camara F, et al: Sequencing of Culex quinquefasciatus establishes a platform for mosquito comparative genomics. Science New York, NY 2010, 330(6000):86-88

67. Nene V, Wortman JR, Lawson D, Haas B, Kodira C, Tu ZJ, Loftus B, Xi Z, Megy K, Grabherr M, et al: Genome sequence of Aedes aegypti, a major arbovirus vector. Science New York, NY 2007, 316(5832):1718-1723.

68. Holt RA, Subramanian GM, Halpern A, Sutton GG, Charlab R, Nusskern DR, Wincker $P$, Clark AG, Ribeiro JM, Wides $R$, et al: The genome sequence of the malaria mosquito Anopheles gambiae. Science New York, NY 2002, 298(5591):129-149

69. Calvo E, Sanchez-Vargas I, Kotsyfakis M, Favreau AJ, Barbian KD, Pham VM, Olson KE, Ribeiro JM: The salivary gland transcriptome of the eastern tree hole mosquito, Ochlerotatus triseriatus. J Med Entomol 2010, 47(3):376-386.

70. Calvo E, Dao A, Pham VM, Ribeiro JM: An insight into the sialome of Anopheles funestus reveals an emerging pattern in anopheline salivary protein families. Insect Biochem Mol Biol 2007, 37(2):164-175.

71. Valenzuela JG, Francischetti IM, Pham VM, Garfield MK, Ribeiro JM: Exploring the salivary gland transcriptome and proteome of the Anopheles stephensi mosquito. Insect Biochem Mol Biol 2003, 33(7):717-732.

72. Ribeiro JMC, Arca B: From sialomes to the sialoverse: An insight into the salivary potion of blood feeding insects. Adv Insect Physiol 2009, 37:59-118.

doi:10.1186/1471-2164-14-875

Cite this article as: Chagas et al:: A deep insight into the

sialotranscriptome of the mosquito, Psorophora albipes. BMC Genomics 2013 14:875 